\title{
Inversion of provenance data and sediment load into spatially varying erosion rates
}

\author{
Fien De Doncker, ${ }^{1 *}$ iD Frédéric Herman ${ }^{1}$ and Matthew Fox ${ }^{2}$ \\ ${ }^{1}$ Institute of Earth Surface Dynamics, Université de Lausanne, Lausanne, Switzerland \\ ${ }^{2}$ UCL Earth Science, University College London, London, UK
}

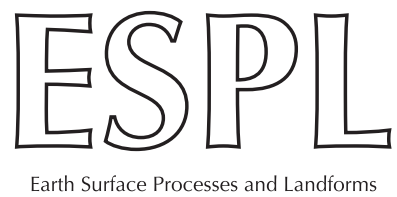

\begin{abstract}
Sediment fingerprinting methods aim to determine the relative contribution of different source areas in detrital sediments based on natural properties - fingerprints - of the source areas. Here, we use U/Th- $\mathrm{Pb}$ age signatures as fingerprints, assuming that the age signal is not altered during erosion-transportation-deposition events, and given that recent technological advances enable precise dating of large amounts of grains. We introduce a formal inversion method that allows to disentangle the amalgamation of source contributions in detrital zircon data and enables to convert this information into an erosion rate map starting from the spatial distribution of zircon age signatures. Relying on the least-squares method and using prior and covariance information to deal with non-uniqueness, we show, using synthetic and natural examples, that we are able to retrieve erosion rate patterns of a catchment when the age distribution and zircon fertility for each source area are well known. Moreover, we show that not only zircon age fingerprints but also other tracers such as mineral content can be used. Furthermore, we found that adding data from samples taken at the outlet of tributaries improves the estimation of erosion rate patterns. We conclude that the least squares inverse model applied to detrital data has great potential for investigating erosion rates. () 2020 John Wiley \& Sons, Ltd.
\end{abstract}

KEYWORDS: formal inversion; provenance analysis; erosion rates; U/Pb zircon ages; detrital zircon data

\section{Introduction}

Erosion and sedimentation processes entail the removal, transport and deposition of sediments. During transport, grains from different source areas are mixed, and sediments reflect the relative contributions from these source areas (Sorby, 1849; Haddadchi et al., 2013). Sediment fingerprinting or provenance analysis methods aim to identify the origin of individual grains by analysing natural properties (fingerprints) that reflect the grains' source (Wall and Wilding, 1976; Wood, 1978; Oldfield et al., 1979). Common fingerprints are grain size (e.g. Kurashige and Fusejima, 1997; Weltje, 2012), magnetism of minerals (e.g. Yu and Oldfield, 1993; Hatfield and Maher, 2009), colour of grains (e.g. Grimshaw and Lewin, 1980; Barthod et al., 2015), stable isotopes (e.g. Fox and Papanicolaou, 2008; Yang et al., 2008), cosmogenic radionuclides (Perg et al., 2003), geochemical components (Collins and Walling, 2002), carbonaceous matter (e.g. Herman et al., 2015; Nibourel et al., 2015) and mineralogical properties (e.g. Eberl, 2004; Gingele and De Deckker, 2005). Here, we use zircon age distributions, which are frequent provenance analyses tools (e.g. Grauert et al., 1973; Pell et al., 1997; Fedo, 2003; Gehrels, 2014; Guo et al., 2018), as fingerprints to infer the spatial variation in erosion rates.

Zircons, minerals that are omnipresent in Earth's crust, contain information about the time since (re)crystallization - for
Gyr to kyr timescales - in their U/Th-Pb ratio (Tilton et al., 1955). This information is preserved during the rock cycle so, often, lithologies with a specific magmato-tectonic and sedimentary history have unique age distributions (Tilton et al., 1955; Vermeesch, 2012). However, recycling can result in identical age distributions for rocks with different histories (Dickinson et al., 2009). In the case of granitic rocks, this distribution may be relatively narrow, but it can be complex for sedimentary rocks. With the advent of SIMS and LA-ICP-MS technologies, single-grain $\mathrm{U} / \mathrm{Th}-\mathrm{Pb}$ dating of zircon crystals became very efficient and cost effective, allowing characterization of multiple source areas in a short period of time (Keller et al., 2017). Here, we define source areas as geological units that each have unique and known U/Th-Pb-age distributions, but the methodology introduced here can be generalized to any other tracer or source area set.

Assuming that every source area is characterized by a different zircon age distribution, the zircon age data of the detrital sediments can be unmixed to quantify the contribution of the different sediment sources (e.g. Amidon et al., 2005; Garzanti, 2016; Saylor et al., 2019). Contrary to sediment flux studies or point measurements (e.g. van Andel, 1950; Collins and Walling, 2002), one can convert the source contributions to spatially varying erosion rates, given that the source area is known. Zircon age distributions are particularly suitable fingerprints since (1) they are omnipresent in igneous, metamorphic 
and sedimentary rocks, (2) it is now possible to analyse large quantities of zircons (Vermeesch, 2012) and (3) zircons are durable minerals (Vermeesch, 2012). These advantages have led to a rapid increase in the use of detrital zircon data as fingerprints in recent years (Vermeesch, 2012).

However, sometimes winnowing effects occur when agegrain size relationships exist, distorting the source distribution image as same-source samples can appear to originate from very different source areas in this situation (Carson et al., 2002; Augustsson et al., 2018; Ibañez-Mejia et al., 2018). This challenge can be overcome by sampling sediments from a wide range of grain sizes (Ibañez-Mejia et al., 2018). Furthermore, Pb loss may occur during subsequent geological events or long-term $\mathrm{Pb}$ mobilization (Mezger and Krogstad, 1997). Regardless, such effects can contribute to the development of a unique signature of ages that is characteristic of rocks that evolved together (Shaanan et al., 2019).

The objective here is to infer how erosion rates vary in space within a catchment or drainage basin by formally inverting detrital $\mathrm{U} / \mathrm{Th}-\mathrm{Pb}$ age distributions. This approach requires an estimation of the mean erosion rate of the catchment and zircon age data representative for the different source areas (lithological units or catchments). Mean erosion rates can, for example, be estimated using the sediment load or cosmogenic nuclide concentration data (Nishiizumi et al., 1986; Guillon et al., 2015).

The formal method that we use here is the least-squares method (Legendre, 1805) including a priori information (Jackson, 1979; Tarantola, 2005), which is a well-established approach to deal with the non-uniqueness of the solution to an inverse problem. The least-squares method has the advantage that it is relatively easy to compute and it enables uncertainties to be propagated from the data to the inferred solution (Jackson, 1979; Tarantola, 2005). This type of inversion is common in geophysics (e.g. Aster and Thurber, 2013; Everett, 2013) and has been applied to geomorphic problems (Herman et al.,
2013; Fox et al., 2014, 2015), but its application for the determination of spatially varying erosion rates from detrital data is new. Braun et al. (2018) recently used age distributions to determine erosion rates but, contrary to their study, we use the least-squares method with an a priori knowledge of the spatial distribution of age clusters.

We start with a description of the forward problem and then explain the inversion approach. We then apply the inversion scheme to synthetic examples, where we highlight the most important parameters and their influence on the estimated erosion pattern. Finally, we present the application of the method to a natural example: the Rio Mendoza catchment, Argentina. With a second natural example of the Marsyandi catchment (Central Nepal Himalayas), we illustrate the versatility of our inversion scheme by using mineralogical tracer data and by redefining source areas as tributary catchments.

\section{Theory}

\section{Forward problem}

Before inverting data, one must formulate the forward problem, in which data are computed starting from a known model. We assume a catchment in which tracers contained in the bedrock are eroded and subsequently transported to the outlet of the catchment. The model is an erosion rate map and the data are tracer concentrations found in the sediments at the outlet.

In this study, tracers are specific age intervals, or bins, of known age distributions (Figure $1 \mathrm{~b}$ ), which are transported as passive tracers. Note that this approach can only be used when zircon fertility data are available and when sufficient zircon grains are collected and analysed (Vermeesch, 2004). Since each lithological unit has a unique signature of tracer a) Erosion rate

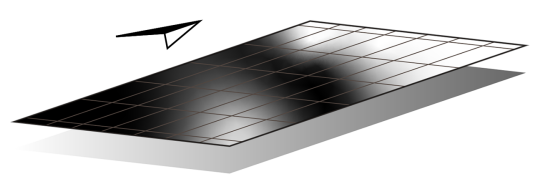

High

Low

\section{b) Geology}

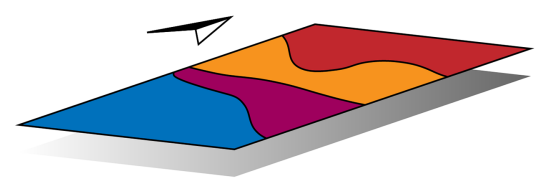

Tracer 1

Freq.
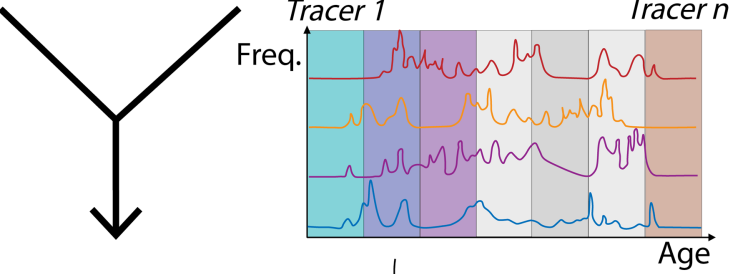

C) River network
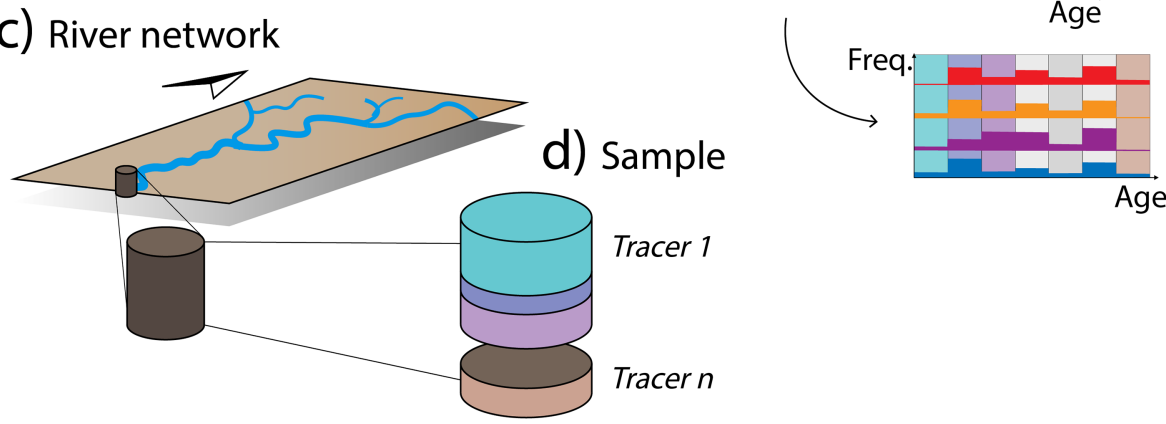

Age

Figure 1. Schematic representation of the forward model: (a) model: erosion map displaying the bedrock erosion rate for every grid cell of the catchment; (b) quantitative model: geological map displaying information about the spatial distribution of zircon concentrations with known age distributions (note that tracers correspond to age intervals); (c) catchment with a sediment sampler at the outlet; (d) concentration of the different tracers found in the sediments. [Colour figure can be viewed at wileyonlinelibrary.com] 
concentrations, after erosion, grains of certain ages can be found in different concentration at the outlet of the catchment. This is the basic principle on which the method relies. The tracer concentration in each source area depends on (1) the mineral zircon concentration in the source rock (often referred to as zircon fertility; Moecher and Samson, 2006), essential for grasping the sediment fluxes in a catchment (e.g. Malusà et al., 2016; Vezzoli et al., 2016) and (2) the relative frequency of zircons within each age interval. These two factors change from one unit to the other, generating independent sets of fingerprints. To construct the tracer concentration maps, one needs to date the zircons of samples representative for every source area. Afterwards, we build an age-frequency histogram for each unit, displaying the frequency by which a grain with a certain age is found. Conveniently, each bin of this histogram can be seen as an individual tracer, and can then be converted into a concentration, using the zircon fertility data (Figure $1 \mathrm{~b}$ ).

The data (Figure 1d) can be seen as the weighted average of the tracer concentrations (Figure $1 \mathrm{~b}$ ), the weights being the different erosion rates (Figure 1a) of the catchment (Figure 1c), which, for a given age interval $n$, can be stated as

$$
\begin{aligned}
d_{n} & =\frac{\int_{\mathscr{A}} e(A) G_{n}(A) \mathrm{d} A}{\int_{\dot{\mathscr{A}}} e(A)} \\
& =\frac{\int_{\dot{\mathscr{A}}} e(A) G_{n}(A) \mathrm{d} A}{Q_{s}}
\end{aligned}
$$

where $d_{n}$ is the data for tracer $n, \mathscr{A}$ is the domain area for which we want to calculate $d, e\left(A_{i}\right)$ is the erosion rate (m $\mathrm{yr}^{-1}$ ) for a given position $A_{i}, G_{n}\left(A_{i}\right)$ is the concentration of zircons of age bin $n$ at position $A_{i}$ and $Q_{s}$ is the total volume of eroded sediments per year. Discretization of this equation gives

$$
d_{n}=\frac{1}{Q_{s}} \sum_{i=1}^{m} e(i) G_{n}(i) \Delta A
$$

where $m$ is the number of pixels for which $d_{n}$ is calculated; $e(i)$ is the erosion rate at pixel $i$ and $G_{n}(i)$ is the concentration of zircons of age bin $n$ at pixel $i$ and $\Delta A$ is the area of each pixel.

Now that the catchment is discretized in cells with a known area $\Delta A$, the model can be represented as the millimetres of bedrock removed each year at each grid cell of the catchment. The spatial information of fingerprint concentrations - the matrix containing this information is called the forward operator - forms the link between the data one wants to compute in the forward problem and the model. One can imagine the forward operator $(\mathbf{G})$ as a stack of maps, where every map displays the concentration of a certain tracer. The number of maps in this stack is equal to the number of age intervals, which is equal to the number of tracers. Hence, for every grid cell, we know the concentration of every tracer.

Assuming the data will follow a distribution with a given mean and error, the forward problem can be stated as

$$
\begin{aligned}
& \mathbf{d}+\boldsymbol{\epsilon}=\mathbf{G} \cdot \mathbf{e} \\
& {\left[\begin{array}{c}
d_{1} \\
d_{2} \\
\cdot \\
\cdot \\
d_{n}
\end{array}\right]+\boldsymbol{\epsilon}=\left[\begin{array}{ccc}
g_{1,1} & g_{1,2} & g_{1, m} \\
g_{2,1} & \cdot & \cdot \\
\cdot & \cdot & \cdot \\
g_{n, 1} \cdot & \cdot & g_{n, m}
\end{array}\right] \cdot\left[\begin{array}{c}
e_{1} \\
e_{2} \\
\cdot \\
\cdot \\
\cdot \\
e_{m}
\end{array}\right]}
\end{aligned}
$$

where $d$ is the data displaying the concentrations for tracer 1 to $n$ in the outlet sediments, $\epsilon$ denotes the error on the data, $\mathbf{G}$ is an $n \times m$ forward operator containing tracer concentrations

\section{a) Erosion rates}

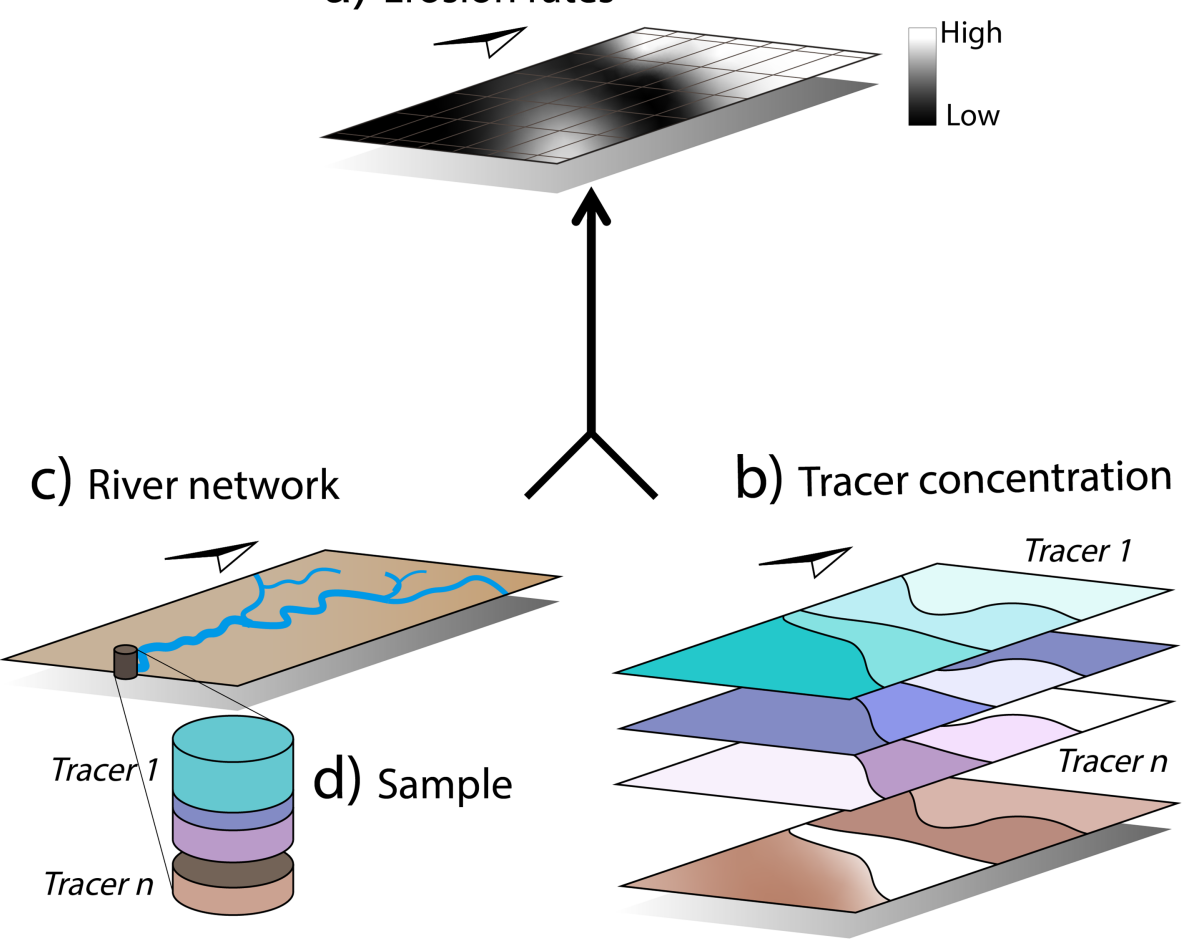

Figure 2. Schematic representation of the inverse model: (a)erosion map displaying the bedrock erosion rate for every grid cell of the catchment; (b) tracer concentration maps; note that the tracer concentration patterns follow the geological patches; (c) catchment with a sediment sampler at the outlet; (d) concentration for every tracer found in the eroded sediments that were collected at the catchment outlet. [Colour figure can be viewed at wileyonlinelibrary.com] 
for every pixel ( $m$ is the number of pixels and $n$ is the number of tracers) and $\dot{\mathbf{e}}$ is the erosion rate model.

\section{Inverse model}

Problem statement

The inverse problem is the computation of the model parameters from given data. This means that an erosion map (Figure $2 a$ ) is calculated starting from tracer concentration maps (Figure 2b) and from detrital tracer concentration data (Figure 2d) sampled at the outlet of the catchment (Figure 2c). Within one lithological unit, we assume the tracer concentration variability to be zero (Figure $2 b$ ).

Looking at Equation (3), one can see that the inverse problem is under-determined: the number of unknowns ( $m$, number of pixels for which the erosion rate needs to be predicted) is larger than the number of data ( $n$, number of tracers or discrete age intervals). To constrain the erosion rates, two different strategies are applied at the same time: (1) using a prior estimation of the erosion rates - for example, equal to the mean erosion rate derived from sediment discharge data; and (2) smoothing, in the form of a spatial covariance matrix, describing the expected correlation between pixels, controlling the expected variance around the prior erosion rates (Jackson, 1979; Tarantola, 2005). These two strategies make the inverse problem Bayesian. Hence prior assumptions that are otherwise implicitly present to regularize the problem are now made explicit (Jackson, 1979).

To solve the inverse problem we follow Tarantola (2005), so

$$
\dot{\mathbf{e}}=\dot{\mathbf{e}}_{\text {prior }}+\mathbf{C}_{m} \mathbf{G}^{T}\left(\mathbf{G C}_{m} \mathbf{G}^{T}+\mathbf{C}_{d}\right)^{-1}\left(\mathbf{d}-\mathbf{G}_{\text {prior }}\right)
$$

where $\dot{\mathbf{e}}$ is the posterior erosion rate, $\dot{\mathbf{e}}_{\text {prior }}$ is a prior erosion rate, $\mathbf{C}_{m}$ is the model covariance and $\mathbf{C}_{d}$ is the data covariance. Here we define the prior erosion rate using sediment load data. Note that the above equation is a closed form, meaning that no iterations are required to find the optimal solution that minimizes the misfit between the observed and predicted data.

The model covariance is calculated using

$$
C(i, j)=\sigma_{m}^{2} \exp \left(-\frac{d_{i, j}^{2}}{\lambda^{2}}\right)
$$

where $\sigma_{m}^{2}$ is the prior variance, $d_{i, j}$ is the Euclidean distance between point $i$ and point $j$ and $\lambda$ is the smoothing distance which characterizes smoothing.

The data covariance is

$$
\mathbf{C}_{\mathbf{d}}=\sigma_{d}^{2} \mathbf{I}
$$

where $\sigma_{d}^{2}$ is the data variance, $\mathbf{I}$ is the identity matrix and $\mathbf{C}_{\mathbf{d}}$ is a diagonal matrix that contains the data uncertainty.

This means that we can estimate an erosion pattern starting from (1) a prior estimate of the erosion rate, (2) information about the spatial distribution of tracer concentrations, which is estimated from a geological map and U/Th-Pb-dated representative samples, and (3) detrital zircon age data.

The posterior covariance can be approximated by

$$
\mathbf{C}_{\mathcal{M}, \text { post }}=\left(\mathbf{G}^{T} \mathbf{C}_{d} \mathbf{G}+\mathbf{C}_{m}^{-1}\right)^{-1}
$$

where diagonal elements give an estimate of the posterior variance, which can be interpreted as the uncertainty on the model. Divided by the prior model variance, computed as the diagonal of $\mathbf{C}_{m}$, this gives the normalized variance.

To check whether the model parameters (the erosion rate of every pixel) can be predicted independently, the resolution matrix $\mathbf{R}$ can be analysed. The resolution corresponds to

$$
\mathbf{R}=\mathbf{H G}=\left[\mathbf{C}_{m} \mathbf{G}^{T}\left(\mathbf{G C}_{m} \mathbf{G}^{T}+\mathbf{C}_{m}\right)^{-1}\right] \mathbf{G}
$$

where $\mathbf{R}$ is the $m \times m$ resolution matrix and $\mathbf{H}$ is the generalized inverse.

Assuming that a true set of model parameters $\dot{\mathbf{e}}_{\text {true }}$ exists, the forward model can be expressed as $\mathbf{G} \dot{\mathbf{e}}_{\text {true }}=\mathbf{d}_{\text {obs, }}$, where $\mathbf{d}_{\text {obs }}$ is the set of observed data. The inverse model predicts a set of estimated parameters $\left(\dot{\mathbf{e}}_{\text {est }}\right)$ for $\dot{\mathbf{e}}_{\text {est }}=\dot{\mathbf{e}}_{\text {prior }}+\mathbf{H}\left(\mathbf{d}_{\text {obs }}-\mathbf{G} \dot{\mathbf{e}}_{\text {prior }}\right)$ (see Equations (4) and (8)). This means that the expression for $\dot{\mathbf{e}}_{\text {est }}$ can be rewritten as

$$
\dot{\mathbf{e}}_{\text {est }}-\dot{\mathbf{e}}_{\text {prior }}=\mathbf{H}\left(\mathbf{G} \dot{\mathbf{e}}_{\text {true }}-\mathbf{G} \dot{\mathbf{e}}_{\text {prior }}\right)=\mathbf{R}\left(\dot{\mathbf{e}}_{\text {true }}-\dot{\mathbf{e}}_{\text {prior }}\right)
$$

The $n \times n$ model resolution matrix $\mathbf{R}$ is equal to $\mathbf{I}$ when the erosion rate estimation for each pixel is uniquely determined. If not, then the outcome of the inverse model must be interpreted as weighted averages of the true erosion map. Hence the relative importance of off-diagonal elements indicates how much the erosion rates at these locations result from a weighted averaging of $\mathbf{e}_{\text {true }}$ at other locations. There is a well-known trade-off between resolution and variance of the posterior solution (Menke, 1989), as high spatial averaging reduces the errors but also reduces the resolution capacity of the model. To test the goodness of resolution, we compute the difference between the resolution matrix and the identity matrix, which is multiplied by the distance $d_{i, j}$ between point $i$ and point $j$ for which resolution $\mathbf{R}_{i, j}$ has been calculated. In this way, we obtain the Gilbert-Backus (Backus and Gilbert, 1968) spread function:

$$
\operatorname{spread}(\mathbf{R})=\sum_{i=1}^{m} \sum_{j=1}^{m} d_{i, j}\left(R_{i, j}-\delta_{i, j}\right)^{2}=\sum_{i=1}^{n} \sum_{j=1}^{n} d_{i, j} R_{i, j}^{2}
$$

where $\delta_{i, j}$ is the element at position $i, j$ in $\mathbf{I}$, so every pixel has an associated spread function value. The smaller the latter, the less the spread of the resolution and the smaller the averaging of the true solution. High spread function values indicate a highly 'filtered' version of the true model.

To test how the inverse model behaves, first synthetic data are created by running a forward model, having as input a matrix containing information about the spatial distribution of the tracers of interest, and an erosion map. In a second step, this newly created dataset is used as the input of the inverse model, together with the tracer concentration matrix. Third, the output of the inverse model is compared to the true erosion pattern of the forward model. A summary of this approach is illustrated in Figure 3.

\section{Synthetic examples}

To test the sensitivity of the inversion method, we analyse the difference between the true and posterior erosion map, exploring the importance of (1) the number and configuration of geological units; (2) the number of tracers; (3) the error on the data; (4) the model covariance; and (5) incorporating data collected on subcatchments within the larger catchment. We start with a reference example and use it for comparison. In a second part, we will analyse the uncertainty of the inferred solution by means of the resolution, posterior covariance and spread. 


\section{Forward problem}

\section{Inverse problem}

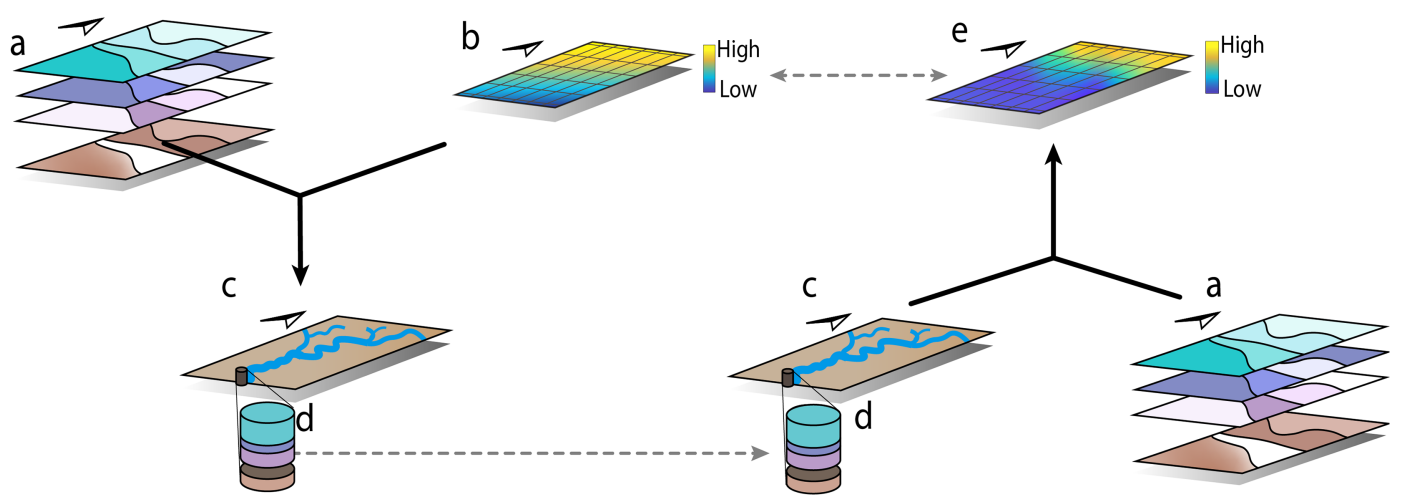

Figure 3. Schematic representation of the forward and inversion procedure. Synthetic data (d) are created in the forward problem using (a) knowledge about the spatial distribution of tracers and (b) a known erosion map. The same data (d) is used as input for the inverse problem together with (a) the tracer information. The result of the inverse problem gives (e), which is then compared to (b). [Colour figure can be viewed at wileyonlinelibrary. com]

\section{Sensitivity tests}

\section{Reference model}

We create synthetic data with the forward model using a step model as 'true' erosion rate pattern and a set randomly generated, unimodal age signatures for every lithological unit as input (for a test with multimodal distributions, see Supporting Information and 'Natural example' section, below). These U$\mathrm{Pb}$ signatures are then split into individual bins to establish tracer concentration maps (Figure 1b).

Keller et al. (2017) showed that the mineral fertility of zircons in granitic rocks is between 10 and $300 \mu g g^{-1}$. Hence every lithological unit is randomly assigned a zircon fertility between 10 and $300 \mu \mathrm{gg}^{-1}$.

We selected a $30 \times 50 \mathrm{~km}$ wide catchment from the output of a landscape evolution model, discretized by square cells of $1 \times$ $1 \mathrm{~km}$. We assume that all the eroded material reaches the outlet of the catchment within a short time period and that the catchment is well connected (e.g. no dams).

We start with 10 distinct geological units (Figure 4d) and 15 age intervals, to generate 15 tracer concentration maps. To fill G, we multiply the tracer concentration in each cell with the zircon fertility at that location and the cell size $\left(\mathrm{m}^{2}\right)$; $\mathbf{e}$ is in $\mathrm{mmyr}^{-1}$ and $\mathbf{d}$ is in $\mathrm{m}^{3} \mathrm{yr}^{-1}$. The smoothing distance is set equal to $2 \mathrm{~km}$, and the prior is equal to the mean erosion rate of the 'true model'. We use a data error of $10 \%$ and a $\sigma_{m}$ of $10^{-2} \mathrm{myr}^{-1}$.

Using these parameters, the posterior erosion map (Figure 4b) corresponds well to the true erosion map (Figure 4a), with differences around the centre of the catchment (Figure 4c). The sum of the absolute difference between the true and posterior erosion map, in other words, the sum of the absolute values of the difference map, is $0.35 \mathrm{myr}^{-1}$. The influence of the spatial distribution of geological units is visible, with boundaries represented by higher posterior variances and the centre of the units by lower values (Figure 4e). Note that for a larger geological unit the posterior covariance at the centre of the unit is higher than for a small unit, expressing the need for spatial variability in tracer concentrations to find a solution close to the true erosion rate. In Figure $4 \mathrm{f}$ the resolution values for the blue dot location also show a clear demarcation of the different geological units. The higher values around the point indicate how much the adjacent geological data play a role in finding a solution for this point. On the spread function map (Figure $4 \mathrm{~g}$ ), where low values indicate locations for which less filtering of data was needed to obtain a solution, the geological patches and borders are also visible. The data created with the posterior erosion map (model data) correspond well to the data created with the true erosion map (Figure 4h); the error bars represent the data error. Inside the data plot, a histogram shows the difference between the true erosion rates and the posterior erosion rates. The residual distribution is close to normal and centred around zero. The right tail indicates a slight bias caused by the smoothing across the sharp boundary.

Sensitivity to the geological model

The inversion approach relies on a good description of the geology of the catchment that is being eroded. To assess the extent to which the geological setting affects the results, we now run the inversion for different geological maps by varying the number of geological units within the catchment from two to eight, keeping all other parameters constant.

With fewer geological units, less spatial variability is generated in the tracer concentration maps and it will be more difficult to recover the true erosion map, as illustrated in Figure 5, where the sum of the absolute difference gradually decreases from 0.7 to $0.25 \mathrm{myr}^{-1}$ as more units are added, compared to $0.35 \mathrm{myr}^{-1}$ for the reference example. It becomes clear that the form of lithological patches also plays a role; when the form of the patches differs strongly from the erosion pattern, it is more difficult to obtain a result close to the true solution. Note that even if the number of tracers were to be increased substantially, without sufficient geological variations we cannot recover the true solution.

Sensitivity to the number of tracers

Another important aspect of the inversion is the number of available tracers, corresponding to the number of discrete age intervals. Instead of using 15 tracers, we decrease the numbers of tracers here to 10 , seven and five to see how the posterior solution responds to this, showing that the true pattern cannot be recovered if only a limited of number tracers is used (Figure 6a). For example, for five tracers, the sum of the absolute differences is as high as $0.45 \mathrm{myr}^{-1}$ (compared to $0.35 \mathrm{myr}^{-1}$ for the reference example) and the erosion rates in the southern part of the catchment are close to the prior erosion rates.

Sensitivity to the data covariance

The data error influences the posterior solution through the data covariance matrix. We calculate $\sigma_{d}^{2}$ as the product between the 

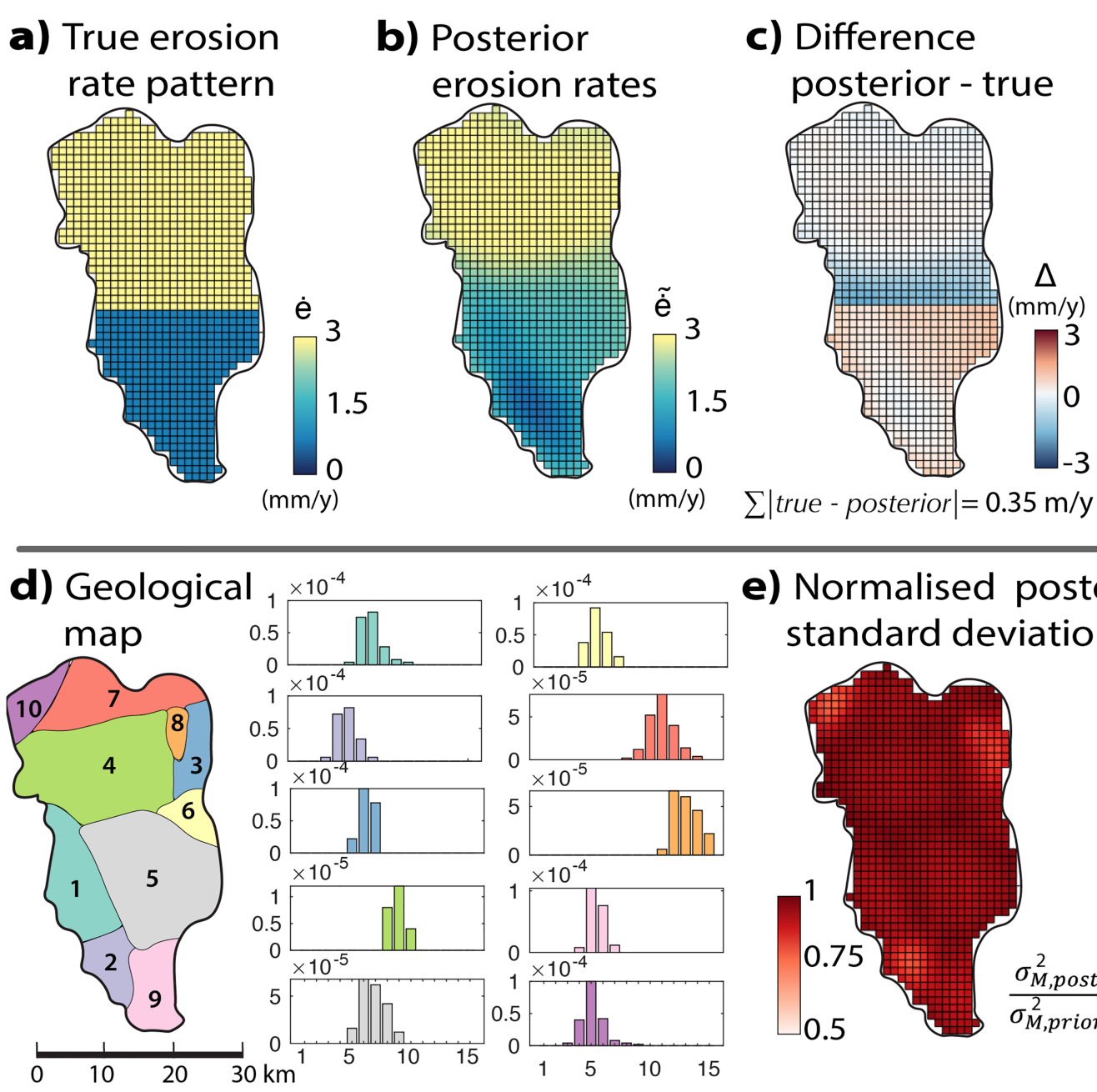

\section{e) Normalised posterior standard deviation}

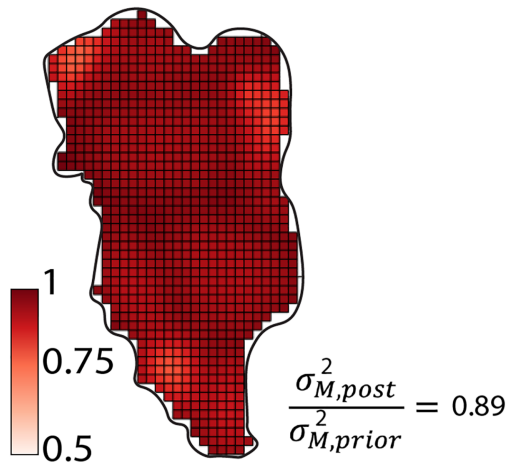

f) Centre point resolution

g) Spread function
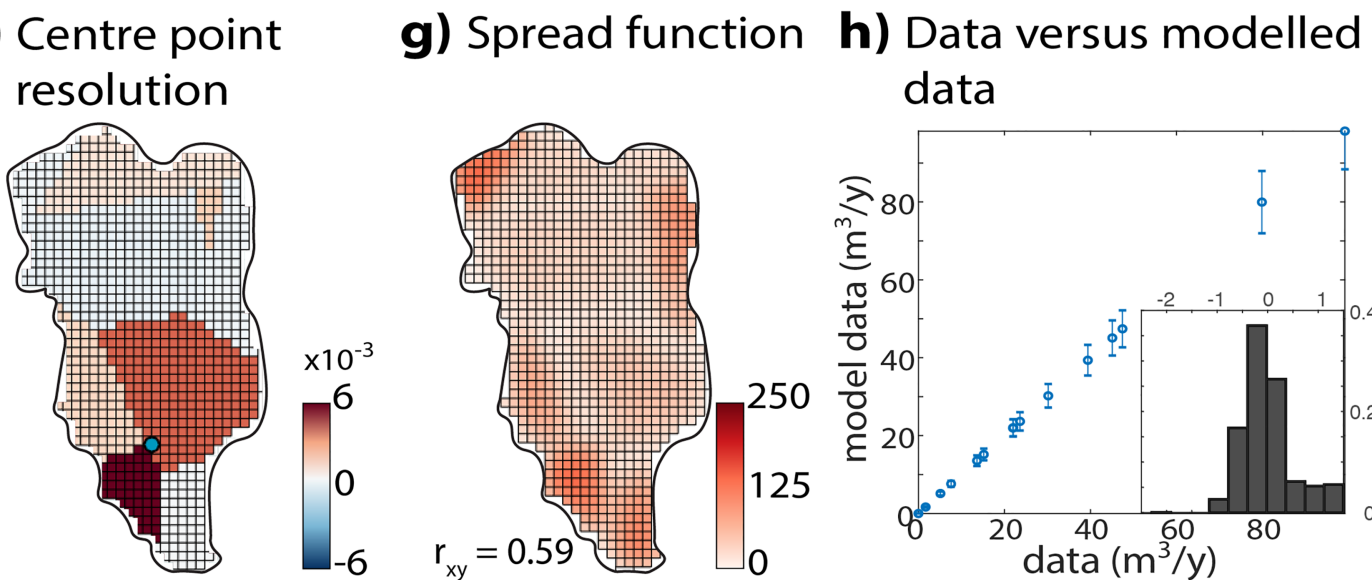

Figure 4. Inversion results for the reference run. (a) True erosion map $\left(\dot{\mathbf{e}}, \mathrm{mmyr}^{-1}\right)$; (b) posterior erosion map $\left(\tilde{\dot{\mathbf{e}}}\right.$, mmyr $\left.^{-1}\right)$; (c) residuals between predicted and inferred erosion rates $\left(\Delta, \mathrm{mmyr}^{-1}\right)$ (underestimations - where the inverse solution is smaller than the true map - are indicated in blue; overestimations are indicated in red); (d) geological map of the catchment; at the right, the unique zircon age signatures are shown for every geological unit (with age in Ma on the $x$-axis and frequency on the $y$-axis); (e) uncertainty on the inverse solution, in the form of the posterior variance. Below the map, the reduced variance is given; (f) resolution values for the dot indicated in blue; (g) spread function values; values closer to 1 indicate locations where less filtering occurs; and $(h)$ inverted data and predicted data using the posterior erosion rate; grey bars represent the relative frequency of

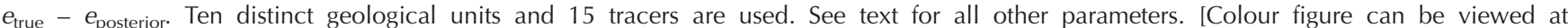
wileyonlinelibrary.com]

data and the error on the data, the latter of which is increased to $30 \%, 60 \%$ and $90 \%$, keeping all parameters identical. A higher data error smooths the posterior solution since confidence in the data has decreased, which increases the difference between the true and posterior solution (Figure $6 \mathrm{~b}$ ). The posterior solution for a data error of $90 \%$ approximates the prior erosion rate, so the true solution cannot be recovered.
Sensitivity to the model covariance

The model covariance describes the variability around the prior erosion, which is controlled by the smoothing distance $\lambda$ and the prior variance $\sigma_{m}^{2}$. First, we tested the impact of $\sigma_{m}$, for which a small value forces the model to approximate the prior erosion rate and therefore only small variations from the prior are permitted. In Figure $6 \mathrm{c}$, we showed the results of an 


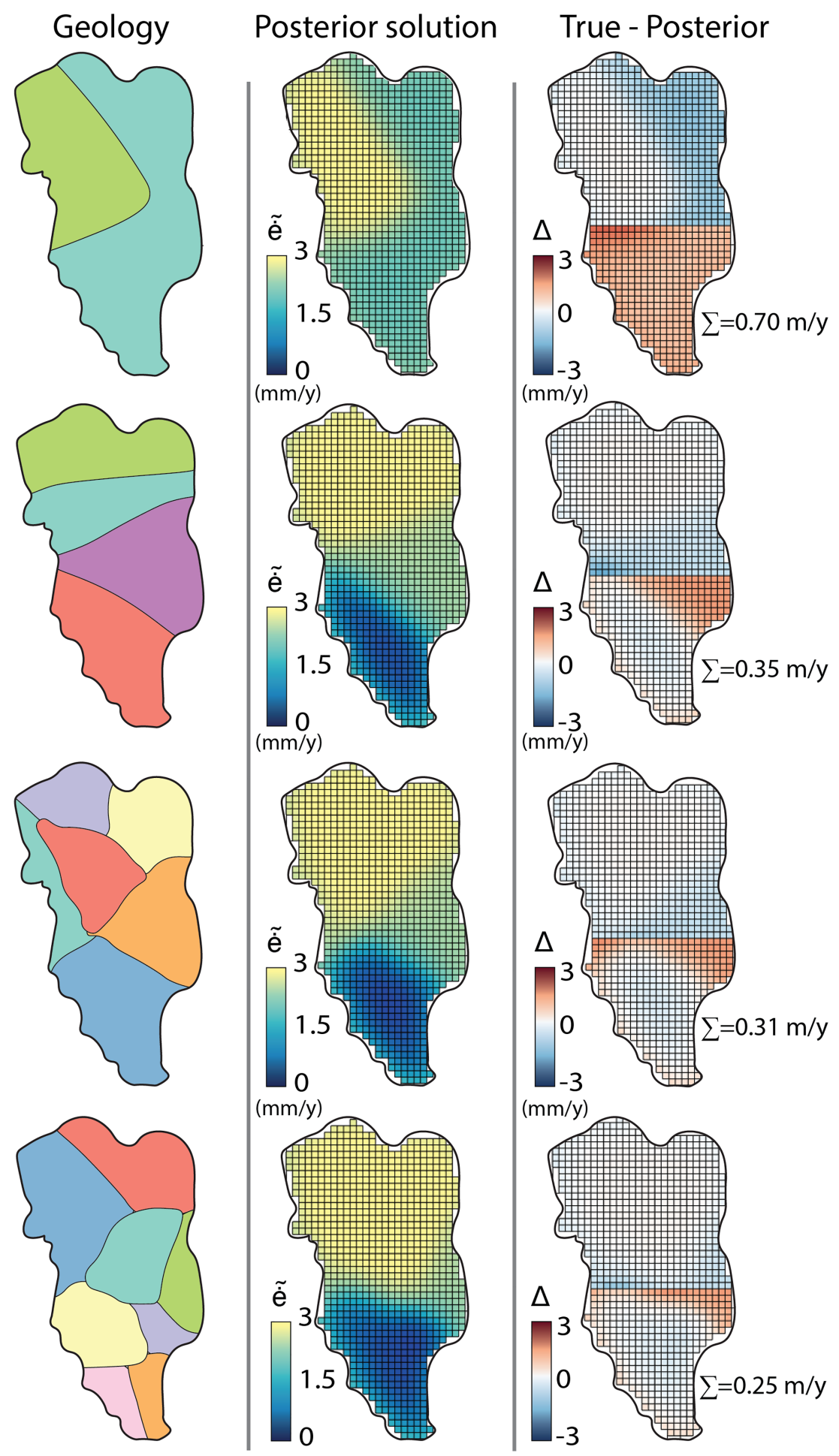

Figure 5. Sensitivity to the number of distinguishable geological units. The number of distinct geological units is varied: 2 , 4, 6 and 8 , from top to bottom (we used 10 geological units in the reference example). The left-hand panels are the geological units; the middle panels are the inferred erosion patterns; and the panels on the right show the difference between the true and the posterior erosion map, with the sum of the absolute difference on the right. [Colour figure can be viewed at wileyonlinelibrary.com]

inversion where $\sigma_{m}$ is increased to $10^{0}$ and $10^{-1}$ and decreased to $10^{-3} \mathrm{~m}^{2} \mathrm{yr}^{-2}$, illustrating that for low prior variances the posterior solution remains close to the prior erosion rate.

Second, we evaluated the influence of the smoothing distance $\lambda$ on the posterior solution. If $\lambda$ is increased, more smoothing is imposed. We set $\lambda$ to 4,10 and $50 \mathrm{~km}$ respectively, showing that for a higher $\lambda$ the difference between the true and the posterior model actually decreases (down to a total of $0.28 \mathrm{myr}^{-1}$ for a smoothing distance of $50 \mathrm{~km}$ ). Remarkably, the solution is similar even for a smoothing distance of an order of magnitude larger that spans the whole domain width (Figure 6d).

Adding subcatchment data to infer more complex erosion patterns

In the experiments above, the data vector $\mathbf{d}$ was filled only with $\mathrm{U}-\mathrm{Pb}$ data from sands sampled at the outlet of the catchment. Now, we add additional zircon age data of sands sampled in different subcatchments of the investigated catchment. These supplementary data can be appended to the existing matrices: 

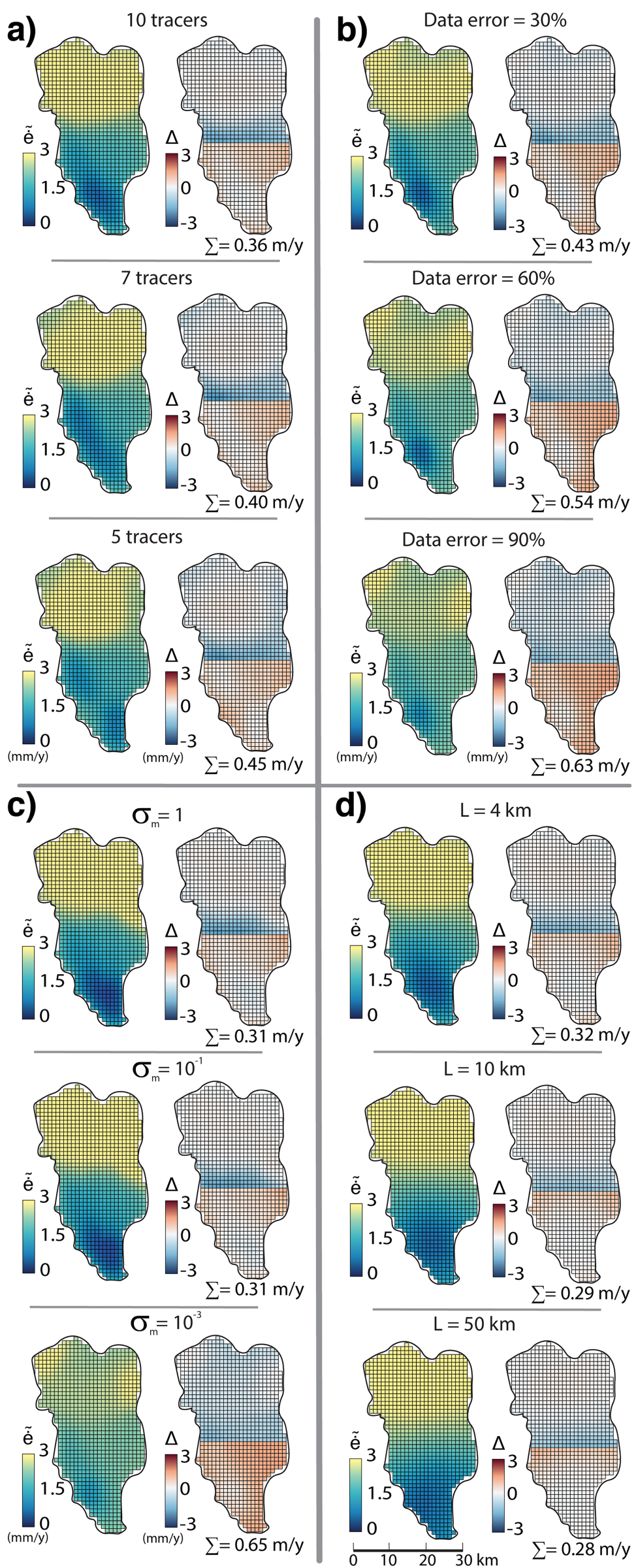

Figure 6. Impact of (a) the number of tracers (number of discrete age bins) (reference: 15 tracers), (b) the error on the data $\left(\sigma_{d}^{2}\right)$ (reference: $\left.10 \%\right)$, (c) the prior standard deviation $\left(\sigma_{m}\right)$ (reference: $10^{-2}$ ) and (d) the smoothing distance $(L)$ (reference: $2 \mathrm{~km}$ ) on the posterior solution (left-hand panels, $\tilde{\mathbf{e}}$, $\mathrm{mmyr}^{-1}$ ) and the difference between the true and posterior model (right panels, $\Delta, \mathrm{mmyr}^{-1}$ ) with the sum of the absolute difference below. [Colour figure can be viewed at wileyonlinelibrary.com] 


$$
\begin{aligned}
& \mathbf{d}+\boldsymbol{\epsilon}=\mathbf{G} \quad \text { e } \\
& {\left[\begin{array}{c}
d_{1} \\
d_{2} \\
\cdot \\
\cdot \\
d_{n}
\end{array}\right]+\epsilon=\left[\begin{array}{ccc}
g_{1,1} & \cdot & g_{1, m} \\
g_{2,1} & \cdot & \cdot \\
\cdot & \cdot & \cdot \\
g_{n, 1} & \cdot & g_{n, m}
\end{array}\right]\left[\begin{array}{c}
e_{1} \\
e_{2} \\
\cdot \\
\cdot \\
\cdot \\
e_{m}
\end{array}\right]} \\
& {\left[\begin{array}{c}
d_{\text {sample } 1,1} \\
d_{\text {sample } 1,2} \\
\cdot \\
\cdot \\
d_{\text {sample } 1, n}
\end{array}\right] \quad\left[\begin{array}{ccc}
0 & g_{1,2} & g_{1, m} \\
0 & \cdot & \cdot \\
\cdot & \cdot & \cdot \\
0 & \cdot & g_{n, m}
\end{array}\right]} \\
& {\left[\begin{array}{c}
d_{\text {sample } x, 1} \\
d_{\text {sample } x, 2} \\
\cdot \\
\cdot \\
d_{\text {sample } x, n}
\end{array}\right]\left[\begin{array}{ccc}
g_{1,1} & 0 & g_{1, m} \\
g_{2,1} & \cdot & \cdot \\
\cdot & \cdot & \cdot \\
g_{n, 1} & \cdot & g_{n, m}
\end{array}\right]}
\end{aligned}
$$

where the new sample 1 is taken at the outlet of subcatchment 1. In the newly appended part of matrix $\mathbf{G}$ for sample 1 , only pixels that lie within subcatchment 1 have the value of the corresponding tracer concentration. Pixels outside of the subcatchment are assigned a value of zero. Note that more than one subcatchment sample dataset can be appended. To test whether these added data help to recover a more complex erosion rate pattern, we use a true erosion map with a chequerboard pattern (Figure 7). The other parameters and the geological map are those of the reference model. First, we evaluate the case where no subcatchment data are appended, i.e. only the tracer concentrations of the sediments at the outlet of the catchment are used in the inversion (grey circle in Figure 7). The resulting posterior pattern is close to the true model, but the sharp boundaries are not well represented. However, already with two additional samples, the sharp borders are better preserved and the total difference between the true and posterior model decreases from 0.68 to $0.46 \mathrm{myr}^{-1}$ and with four additional samples even to $0.43 \mathrm{myr}^{-1}$.

Until now, we have assumed a perfect connectivity throughout the whole catchment. To simulate the case where some eroded material does not reach the outlet within a short timespan, we multiply the erosion rate map by a mask with a value of 0.7 at locations with fewer than two neighbouring water-donor pixels and ones for other pixels (Figure 8). Like this, locations with small discharges deliver $70 \%$ of the actual eroded volume to the outlet.

In this case, when no samples are added, the posterior map is smooth and underestimations occur mainly in the upper part of the catchment where the drainage network is less dense (Figure 8). The total difference between the true and posterior solution is $0.75 \mathrm{myr}^{-1}$ and only decreases to $0.72 \mathrm{myr}^{-1}$ for four added samples. Note how the added samples result in an erosion rate pattern that is overfitted; the influence of the southernmost samples is clearly visible in the patch of higher erosion rates in the south of the catchment. To remove this overfitting effect, we increase the smoothing distance to $8 \mathrm{~km}$, which decreases the total difference to $0.70 \mathrm{myr}^{-1}$. This shows that adding samples helps to alleviate connectivity issues, albeit partly and requiring a larger smoothing distance to avoid overfitting.

\section{Uncertainty analysis: posterior covariance, resolution and spread}

In this section, we analyse the influence of the varying parameters on posterior variance, resolution and spread function. We
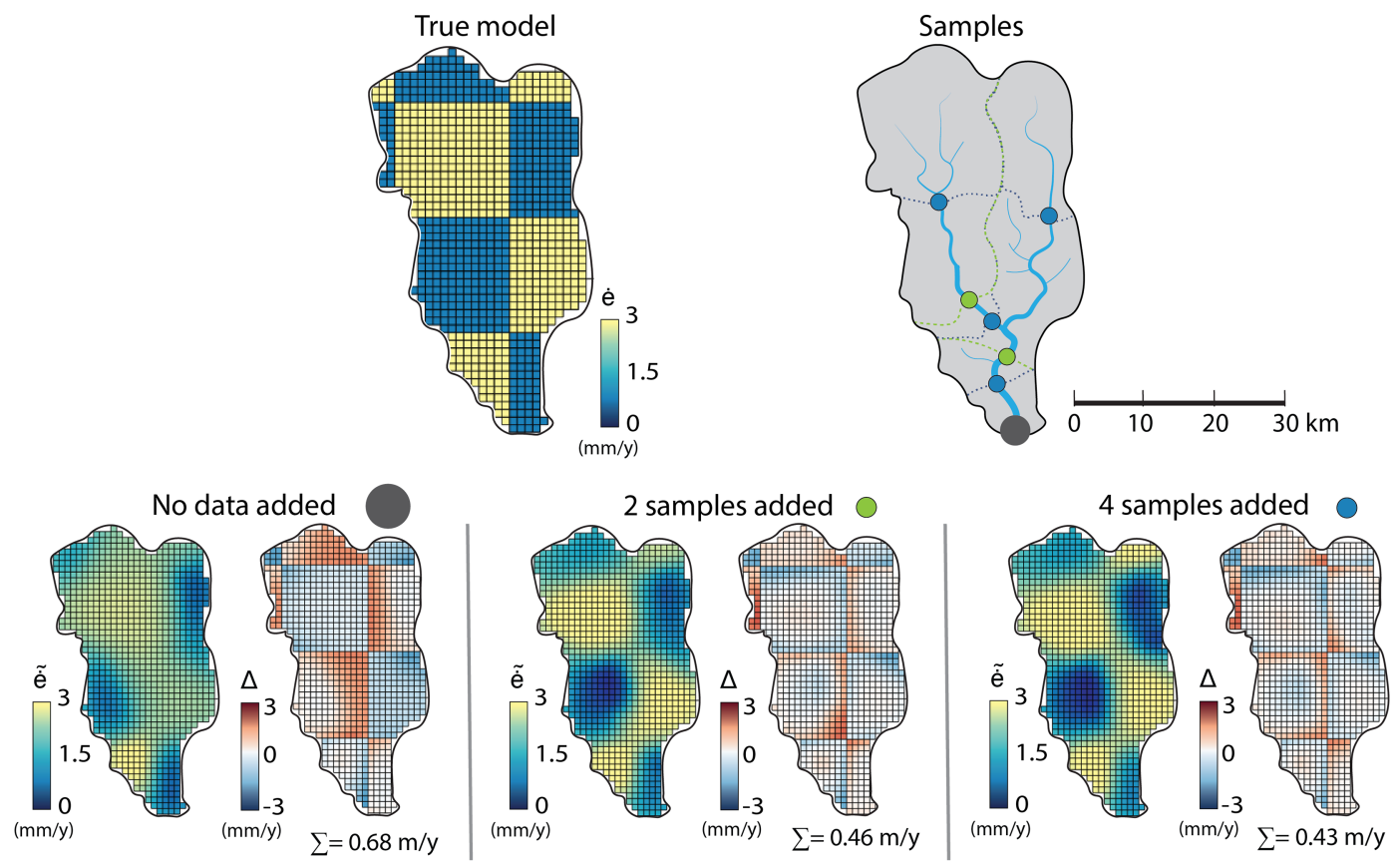

Figure 7. Sensitivity to adding data. The upper right figure displays where the samples have been taken; in the case with two added samples, green circles represent the location of these added samples, and green dotted lines represent their catchment delineations; in the case of four added samples, the location of these added samples is represented by red circles, and red dotted lines represent their catchment delineations. Note that in every case the data of the outlet of the catchment are used, which is represented by a grey circle. In every panel, the left-hand figure represents the posterior solution and the right-hand panel illustrates the difference between the true and posterior erosion rates. [Colour figure can be viewed at wileyonlinelibrary.com] 

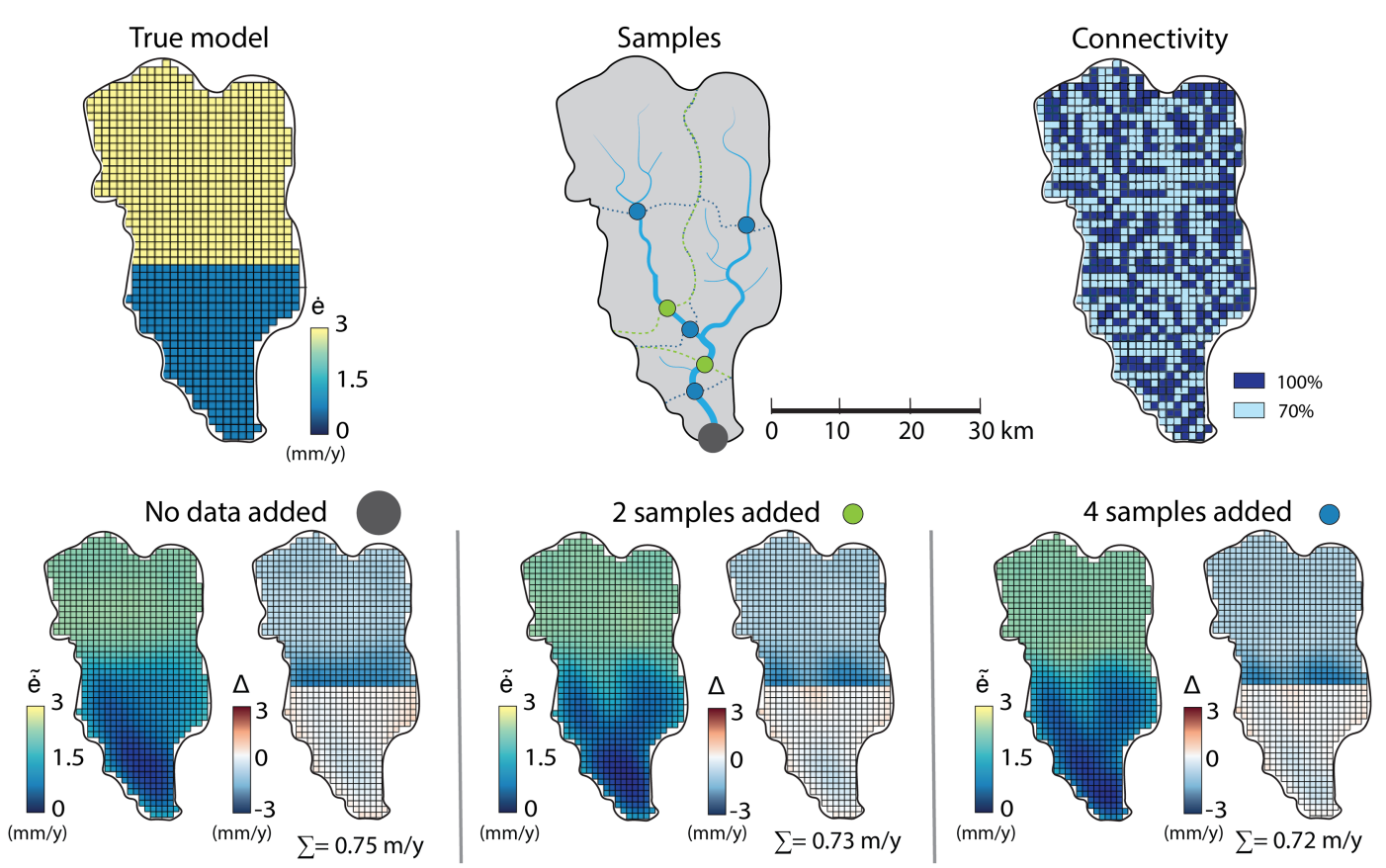

Figure 8. Sensitivity to adding data in a connectivity-limited context. The upper right figure displays where the samples have been taken; in the case with two added samples, green circles represent the location of these added samples, and green dotted lines represent their catchment delineations; in the case of four added samples, the location of these added samples is represented by red circles, and red dotted lines represent their catchment delineations. Note that in every case the data of the outlet of the catchment are used, which is represented by a grey circle. The connectivity mask with which the true erosion model was multiplied to compute the data is shown at the right-hand side. In every panel, the left-hand figure represents the posterior solution and the right-hand panel illustrates the difference between the true and posterior erosion rates. [Colour figure can be viewed at wileyonlinelibrary.com]

plot the normalized posterior standard deviation by mapping $\frac{\sqrt{\operatorname{diag}\left(\mathbf{C}_{M, \text { post }}\right)}}{\sqrt{\operatorname{diag}\left(\mathbf{C}_{M} \text {, prior }\right)}}$. The normalized variance $\left(\frac{\sigma_{M, \text { post }}^{2}}{\sigma_{M \text {, prior }}^{2}}\right)$ represents how much the model has evolved away from the prior estimate; values close to one indicate that the inclusion of data did not improve the solution; in other words, a normalized variance close to one indicates low information content of the data (Menke, 1989; Fox et al., 2014). We map the R-row corresponding to the blue dot location; high values represent locations with data that were needed to constrain the solution for the blue dot location. For a perfect solution, the resolution at the blue dot would be one and all the other pixels would be zero. To assess the diagonality of the resolution matrix, we calculate the sample correlation index $\left(r_{x y}\right)$; a perfectly diagonal matrix corresponds to $r_{x y}=1$. We also map the spread, which, for a perfect solution where $\mathbf{R}=\mathbf{I}$ would be zero everywhere.

A trade-off exists between the model variance and the resolution, as a high resolution allows detection of small features, while a low variance spatially averages errors but no longer enables discernment of sharp boundaries (Menke, 1989).

We follow the same structure as for the sensitivity tests, so we start by reducing the number of geological units, which decreases the reduced variance and decreases the sample correlation coefficient. For fewer geological units, the spread function values are lower than for more geological units. The shapes of the geological patches are clearly visible in the resolution maps, as maxima on the posterior variance maps and as minima on the spread function maps. Figure 9 illustrates the trade-off between variance and resolution at these sharp unit boundaries.

We saw that decreasing the number of tracers makes it more difficult to obtain a solution that is close to the true model. Decreasing the number of tracers increases the reduced variance and decreases the sample correlation coefficient, indicating that every location depends more on the data of other locations because of the lack of data caused by the lower number of tracers (Figure 10a). For five tracers, the patterns change due to a shift in data sparseness, as we simply removed the last 10 age bins. This means that some geological units no longer contain any tracer information, since their relevant age bins have been removed.

Increasing the data error leads to greater differences between the posterior model and known erosion rate map (Figure 10b), since the model remains close to the prior estimate, fitting the data poorly. This leads to a higher reduced variance (even though the effect is small), a slightly lower sample correlation index, lower resolution values and lower spread function values in the south of the catchment.

Together with the smoothing distance, the prior variance $\left(\sigma_{m}^{2}\right)$ governs the model covariance. Increasing the prior variance allows the posterior erosion rate map to deviate more strongly from the prior estimation, while a low $\sigma_{m}$ forces the model to approximate the prior erosion rate distribution (Figure 10c). For higher $\sigma_{m}$ values, the model fits the data well, the reduced variance is lower and the diagonality of the resolution matrix is higher (indicated by a higher $r_{x y}$ value). As for a lower $\sigma_{m}$ more smoothing occurs, more geological units play a role in the resolution map than for a high $\sigma_{m}$. The increased spread function values and increased posterior variance for higher $\sigma_{m}$ values can again be framed in terms of trade-off between variance and resolution, illustrated in Figure 11 with the normalized variance plotted against the spread of the resolution (calculated as the sum of the spread values). Lower model variances coincide with higher spread function values as this corresponds to higher averaging - to obtain a smaller variance - which leads to a worse resolution. The colours in the plot indicate the total difference between the true and the inverse model and show that a reduction in posterior variance leads to solutions closer to the true model, even though the resolution is slightly worse. 

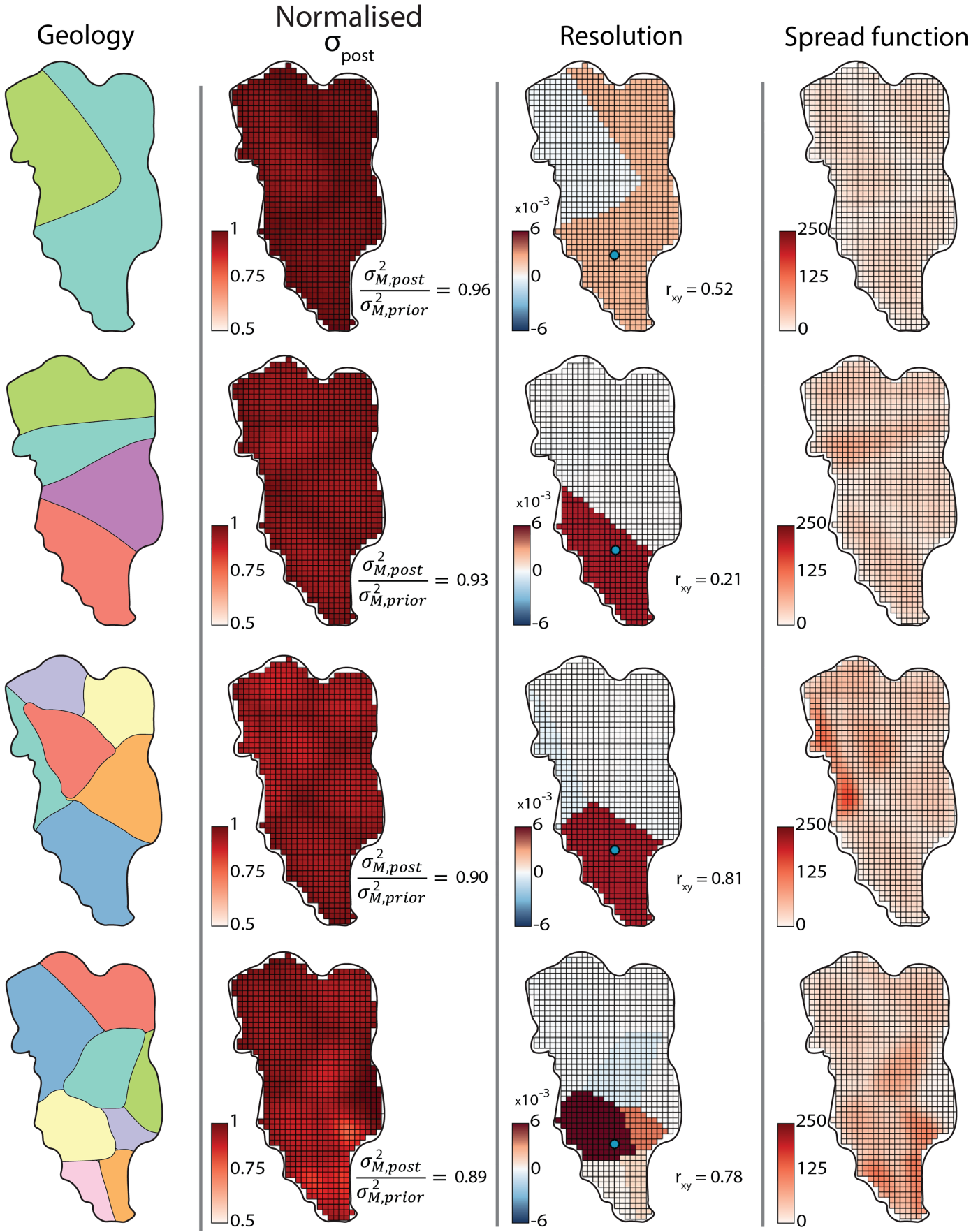

Figure 9. Impact of number of geological units on uncertainty. The left-hand panels show the geological configuration; the middle left-hand panel shows the diagonal of the posterior variance and the normalized variance; the middle right-hand panel shows the resolution for the blue dot location and the sample correlation coefficient; and the right-hand panel shows the spread function values. [Colour figure can be viewed at wileyonlinelibrary. coml

A higher smoothing distance $(\lambda)$ leads to a smooth posterior solution where noise is effectively removed due to high spatial averaging. As a downside, using large smoothing distances, we fail to recover sharp boundaries and small and local variations in erosion rates. In the posterior variance plot, the geological patches have become almost invisible for a high smoothing distance and the reduced variance is very low (Figure 10d). The low-resolution values indicate that the posterior solution at the blue dot depends strongly on information of other, distant locations. In the same way, the spread function values have increased and the shapes of the geological borders have faded, as the smoothing distance is as large as the full domain length.

In the same way as for the $\sigma_{m}$ experiments, the smoothing distance experiments illustrate the trade-off between variance and resolution as, for more spatial averaging, the resolution gets worse (Figure 12).

With added subcatchment data, the posterior solution becomes closer to the true erosion rate map, which is especially useful when solving for more complex erosion rate patterns (Figure 13). At the new sample locations, posterior variances are low and the reduced variance decreases when more samples are added. The posterior solution of the blue dot is controlled by a very small range of other locations as the resolution values have increased - because of better data - and are only important in the near vicinity of the blue dot, illustrating the overfitting risk. The spread function values have increased due to the high resolution values (Figure 13). 

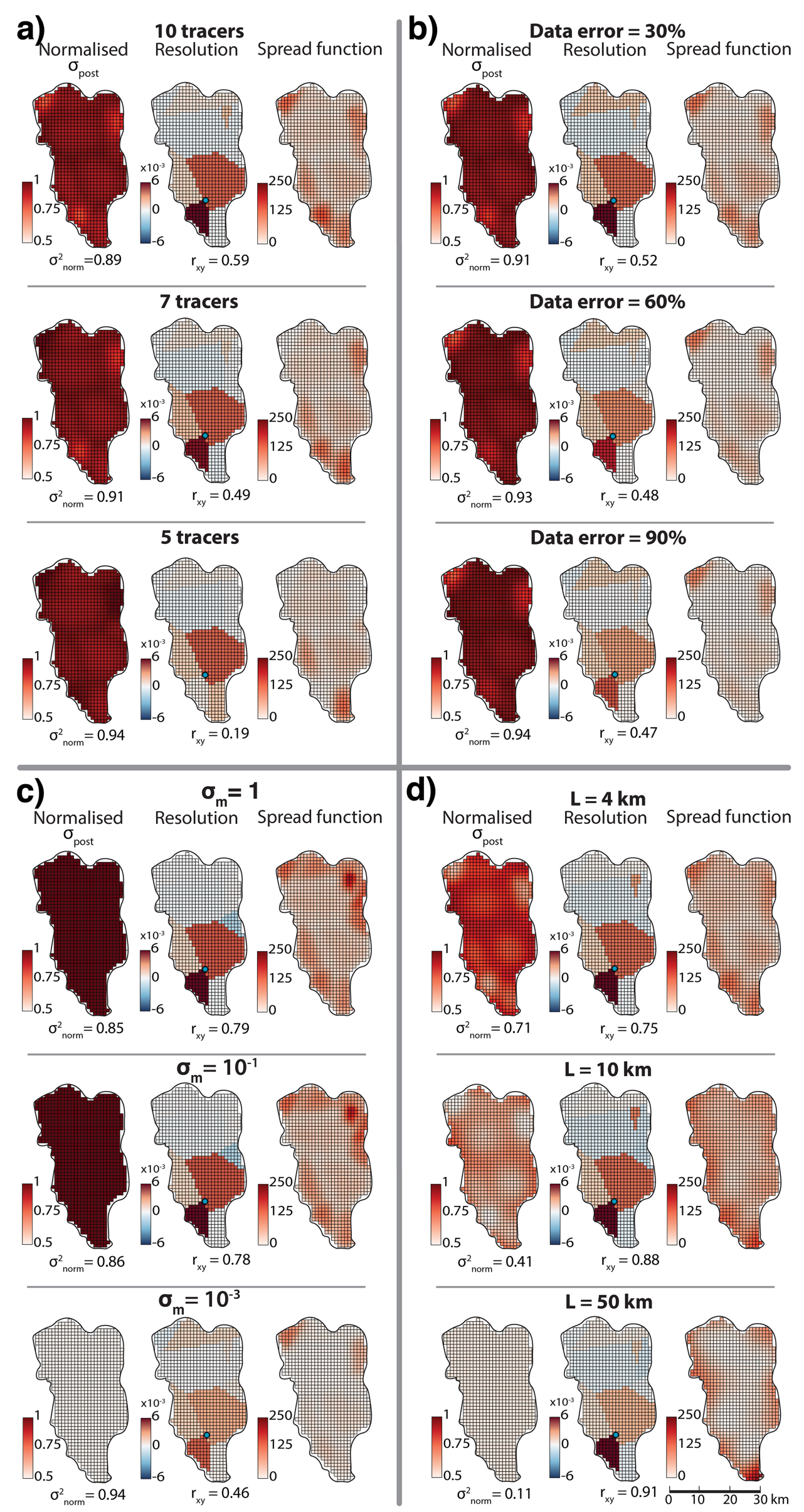

Figure 10. Impact of (a) the number of tracers (discrete age bins) (reference: 15$)$, (b) the error on the data $\left(\sigma_{d}^{2}\right)$ (reference: $\left.10 \%\right)$, (c) the prior standard deviation $\left(\sigma_{m}\right)$ (reference: $10^{-2}$ ), and $(\mathrm{d})$ the smoothing distance $(L)$ (reference: $2 \mathrm{~km}$ ) on the posterior and normalized variance (left-hand panels), the resolution for the blue dot location and the sample correlation coefficient (middle panels) and the spread function (right-hand panels). [Colour figure can be viewed at wileyonlinelibrary.com] 


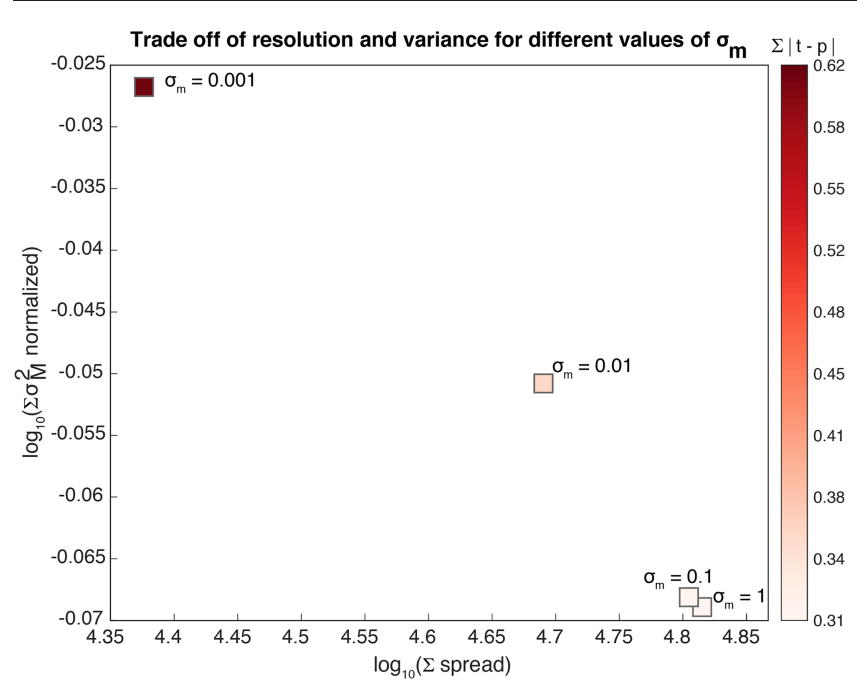

Figure 11. Trade-off between the normalized model variance (sum of diagonal of $\mathbf{C}_{m \text {,post }}$ divided by the sum of the diagonal of $\mathbf{C}_{m}$ ) and the spread of the resolution (sum of the spread matrix) for different values of $\sigma_{m}$. The colours indicate the total difference between the true and posterior model for the different $\sigma_{m}$ values. [Colour figure can be viewed at wileyonlinelibrary.com]

\section{Summary of sensitivity tests}

Our inverse scheme relies on the detection of source-areaspecific zircon age fingerprints in the detrital data, with sufficient variation between the source areas as a primary requisite. First, we tested the impact of the number of distinct source areas. Smaller geological units increase the resemblance between the posterior erosion map and the true erosion map. The opposite is the case for fewer units, especially when the orientation of the source areas is parallel to the true erosion rate gradient. This is also reflected in smaller resolution values and higher normalized variances, since fewer model parameters have been solved independently from other locations. Second, we showed that with more discrete age intervals (tracers) the posterior solution (posterior erosion rate map) is closer to the true solution. However, even for a small number of tracers, an accurate solution can be obtained. As fewer data are available,

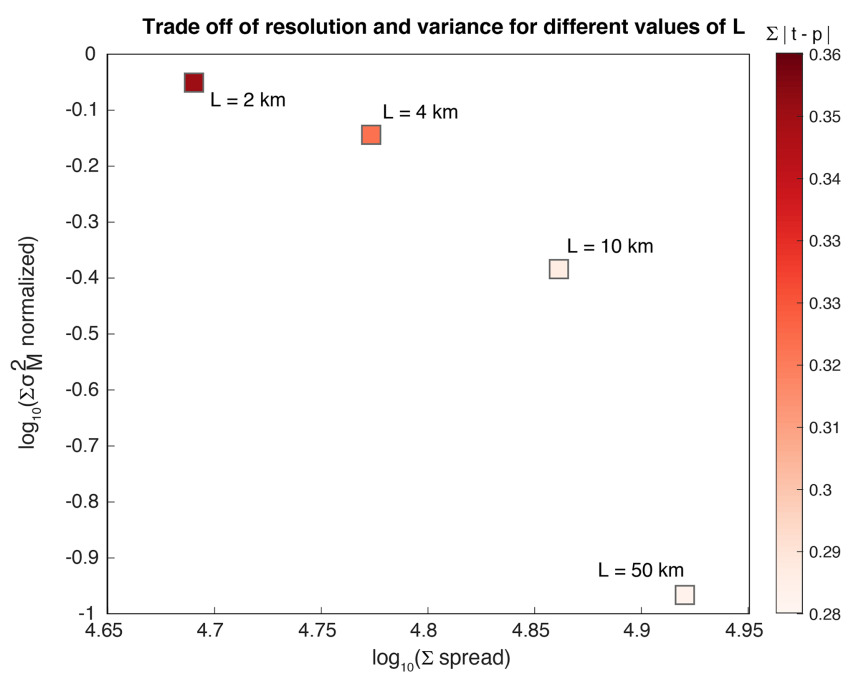

Figure 12. Trade-off between the normalized model variance (sum of diagonal of $\mathbf{C}_{m \text {, post }}$ divided by the sum of the diagonal of $\mathbf{C}_{m}$ ) and the spread of the resolution (sum of the spread matrix) for different smoothing distances. Colours indicate the total difference between the true and posterior model for the different smoothing distances. [Colour figure can be viewed at wileyonlinelibrary.com] more locations depend on information of other locations to constrain their posterior erosion rate, which is reflected in lower resolution values, a higher normalized variance and a lower sample correlation coefficient. Third, we showed that the impact of data uncertainty on the posterior solution is small. Higher data uncertainty leads to a smoothed solution as, in that case, the posterior erosion rate map is less overfitted on the data. The same smoothing occurs for a lower prior variance, which leads to lower resolution values, a higher normalized variance and a lower sample resolution coefficient. The robustness of the model is illustrated with results for a large smoothing distance remaining close to the true solution. A large smoothing distance lowers the resolution, as almost all locations depend on other locations for their posterior solution, which is also reflected in higher spread function values. Finally, we found that appending subcatchment data greatly improves the recovery of more complex erosion rate patterns. To conclude, the method allows us to recover the true model well, when the source areas' signals differ sufficiently. The accuracy of the posterior solution increases mainly with a larger number of distinct source areas, and to a lesser extent with more tracers and by appending subcatchment data.

\section{Natural Example}

\section{Mendoza catchment, Argentina}

Now we will invert natural detrital zircon age data using our inversion scheme. The requirements for a suitable study area areas follows: (1) zircon age data are available for the different lithological units; (2) detrital zircon age data exist for sands sampled at (the outlet of the) river; (3) mineral zircon fertility data are available for the different lithological units; (4) sediment discharge data are available; (5) the catchment is well connected. We could not find any area that fulfils all these requirements, but we decided to use the Mendoza catchment as it offers a suitable dataset (Capaldi et al., 2017), although zircon fertility data remain incomplete.

The Mendoza catchment is situated in the southern central Andes, Argentina, with the western part of the catchment in the Principal Cordillera, the central part in the Frontal Cordillera and the eastern part in the Precordillera. The Principal Cordillera consists of a magmatic arc, geologically characterized by Neogene volcanic and volcaniclastic rocks as well as Neogene fluvial clastic and volcaniclastic rocks (Figure 14), which are the foreland deposits. The Jurassic-Cretaceous clastic and volcaniclastic rocks in the Principal Cordillera are related to deformation due to Mesozoic rifting. The Frontal Cordillera, stemming from a thick-skinned block uplift, includes a Permian-Triassic igneous basement (the Choiyoi group), Neogene volcanic and volcaniclastic rocks, and CarboniferousPermian marine and fluvial clastic rocks. The available datasets for the Mendoza catchment are (1) zircon age data for the geological units (Casquet et al., 2001; Vujovich et al., 2004; Mulcahy et al., 2011; Mackaman-Lofland et al., 2015; McKenzie et al., 2016; Capaldi et al., 2017), (2) detrital zircon age data of multiple points of the Mendoza river (Capaldi et al., 2017), (3) mineral fertility data for two units (Strazzere et al., 2006; Kleiman and Japas, 2009; Maydagán et al., 2011), and (4) sediment discharge data from the infill rate of the Potrerillos reservoir, derived from satellite imagery (Michoud et al., 2016). Furthermore, except for the Potrerillos dam, no large dams exist in the study area.

One can expect high erosion rates in the Principal Cordillera because of its high number of glaciers and high mountain peaks. Furthermore, mean monthly temperatures in the 


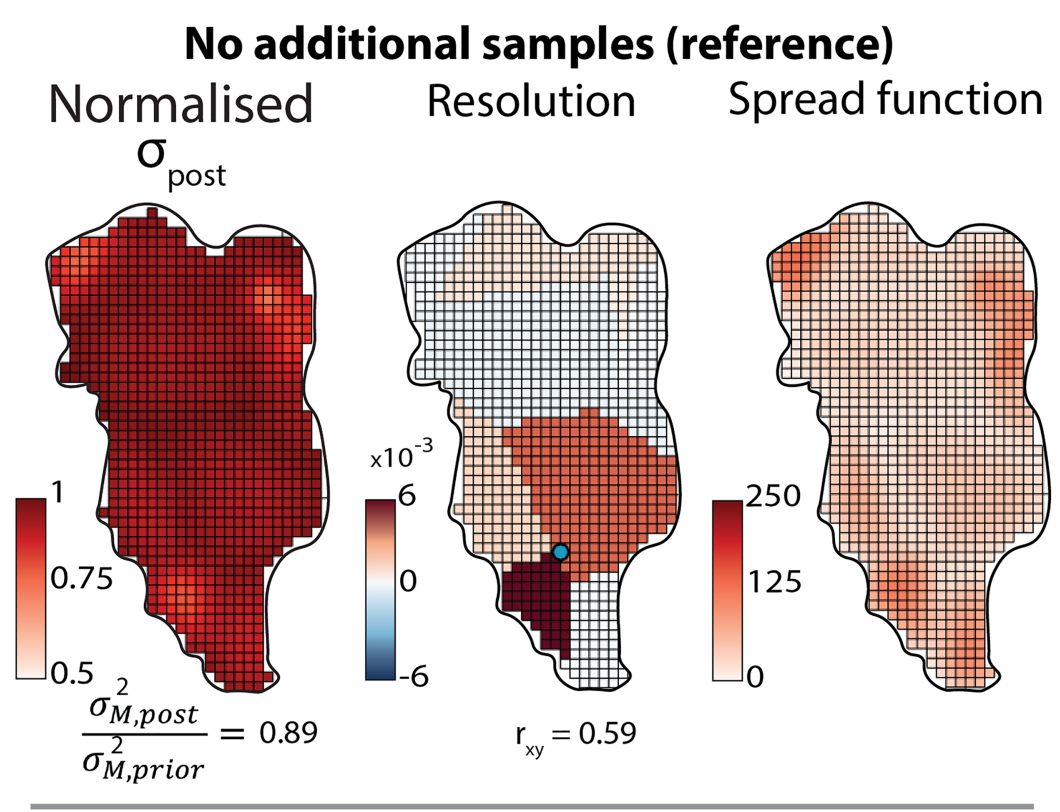

No additional samples (reference)

\section{2 additional samples}

Normalised Resolution Spread function $\sigma_{\text {post }}$

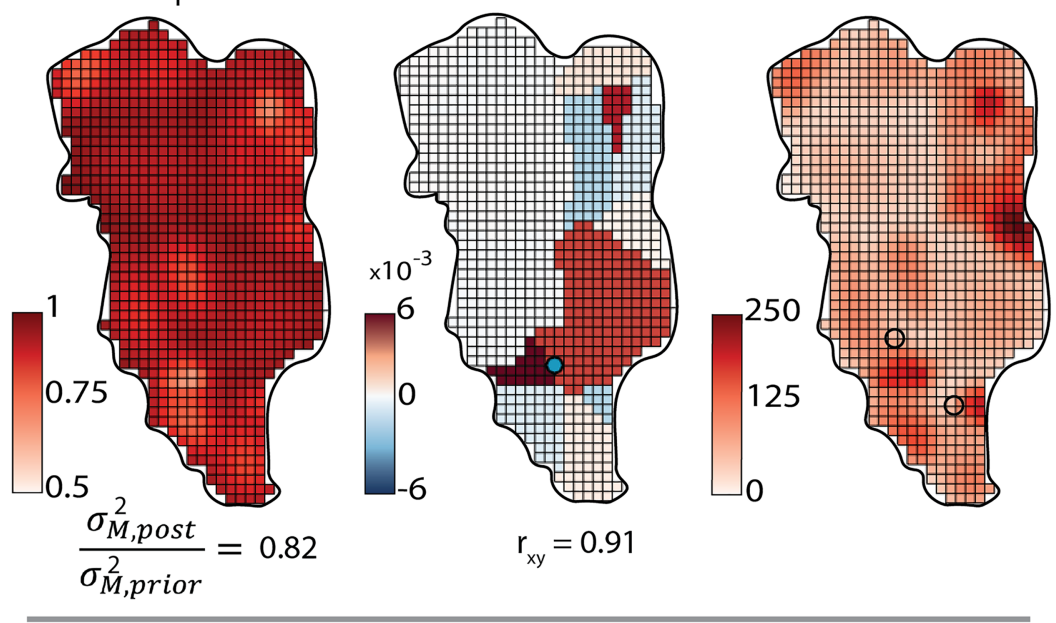

\section{4 additional samples}

Normalised Resolution Spread function
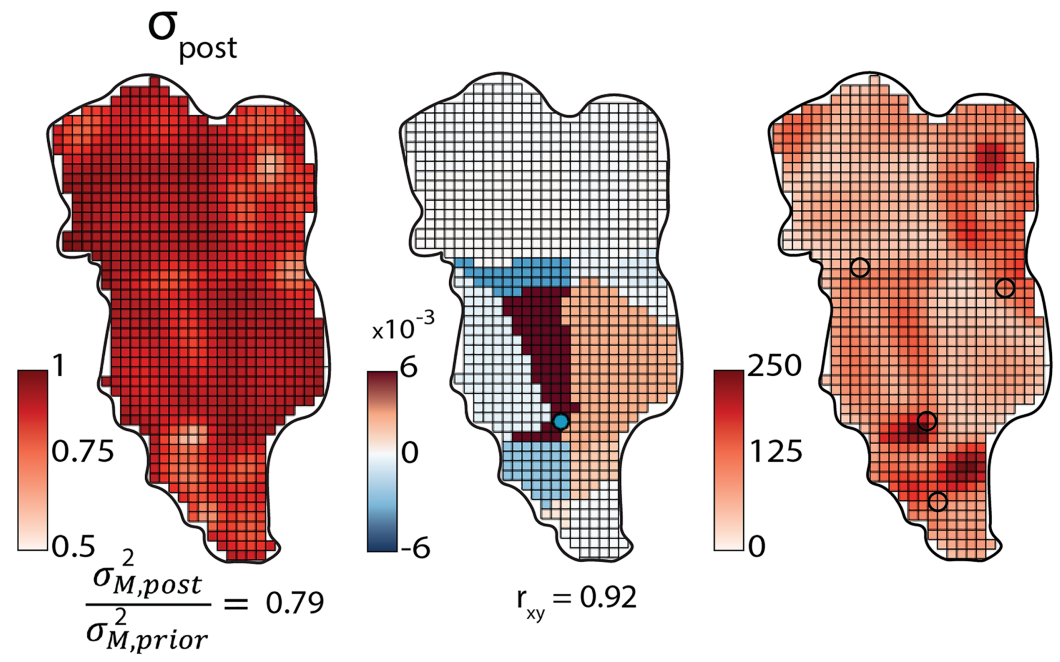

$r_{x y}=0.92$

Figure 13. Impact of adding samples on uncertainty variables. The left-hand panel shows the diagonal of the posterior variance and the normalized variance; the middle panel shows the resolution for the blue dot location and the sample correlation coefficient; and the right-hand panel shows the spread function values. Black dots on the spread function maps indicate the location of the added samples. [Colour figure can be viewed at wileyonlinelibrary.com] 

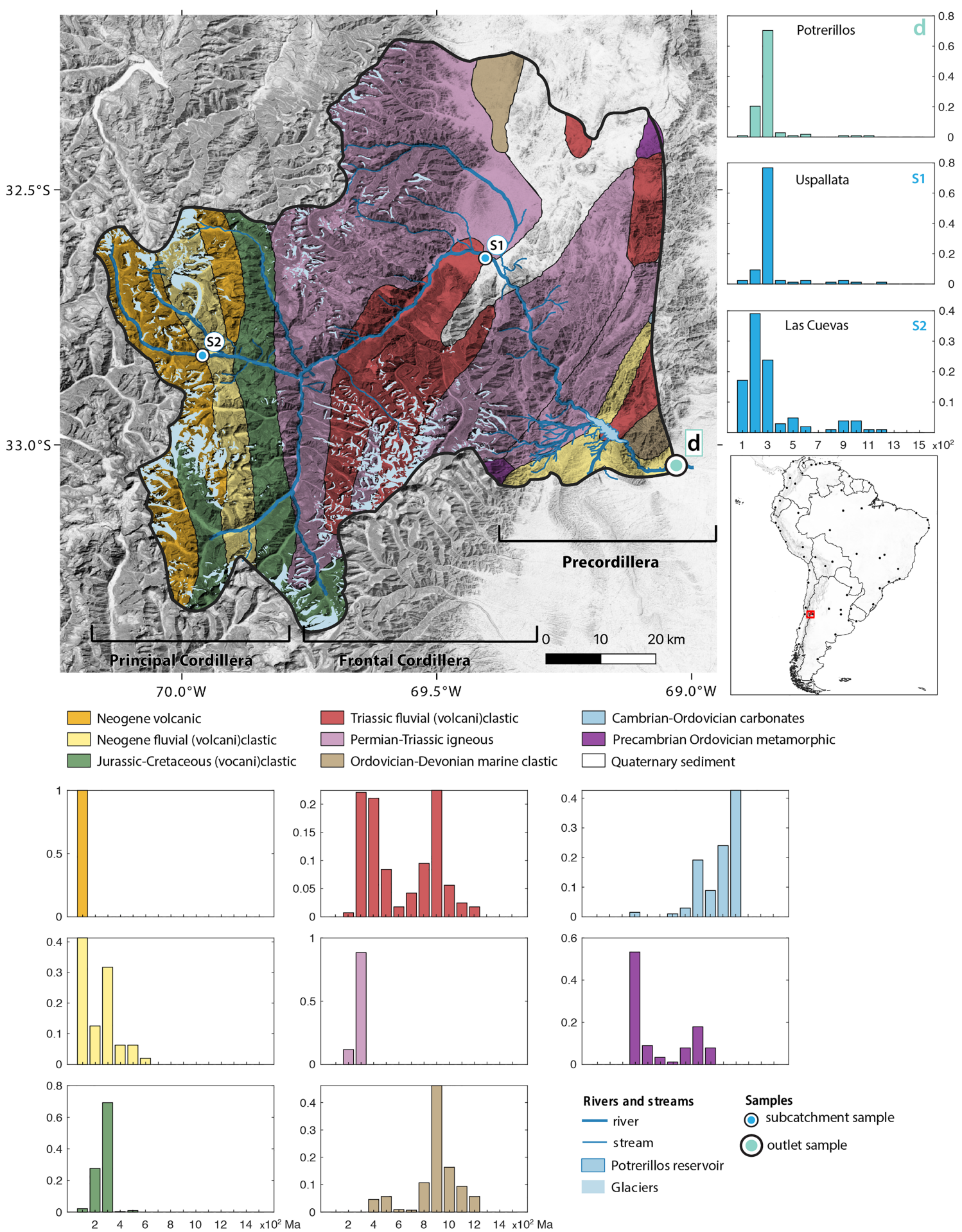

Figure 14. Geology of the Mendoza catchment. At the right, the catchment location is represented by a red square on the overview map. The age signature of each geological unit is indicated at the bottom of the figure and the detrital zircon data are displayed at the right. [Colour figure can be viewed at wileyonlinelibrary.com]

catchment fluctuate strongly throughout the year, between $-7^{\circ} \mathrm{C}$ and $4^{\circ} \mathrm{C}\left(3800 \mathrm{~m}\right.$ a.s.l.) and between $20^{\circ} \mathrm{C}$ and $4^{\circ} \mathrm{C}$ (1200 $\mathrm{m}$ a.s.l.), causing freeze-thaw action to produce loose material that can be transported by glaciers, rivers or mass movements (Michoud et al., 2016). Since the catchment's climate is arid to semi-arid (with a mean annual rainfall of 140 $360 \mathrm{~mm}$ (Crespo et al., 2017)), wind erosion plays an important role too. However, the soil erodibility for wind erosion is very low in the Mendoza catchment, except for the north-north-east of the catchment (Figure 15a) (Cremades et al., 2017). Using the universal soil loss equation (USLE Wischmeier, 1960), estimated hydrological erosion is high: up to 30 tha $^{-1} \mathrm{yr}^{-1}$ (actual) and 500 tha $^{-1} \mathrm{yr}^{-1}$ (potential) in the west and down to 1 and $15 \mathrm{tha}^{-1} \mathrm{yr}^{-1}$ in the east (Figure 15b) (Gaitan et al., 2017). Moreover, the tectonic activity of the area and the glacial debuttressing of valley slopes trigger landslides (Michoud et al., 2016). Large debris flows and rock falls occur throughout the whole catchment, often triggered by heavy rainfall or snowmelt events (Michoud et al., 2016). Baumann et al. (2011) mapped the debris flow hazard along the N7 road, which traverses the catchment from east to west, with high hazards on the northern shores upstream of Uspallata and the east-facing slopes between Uspallata and Potrerillos (Figure 15c). 
a) Standard global database
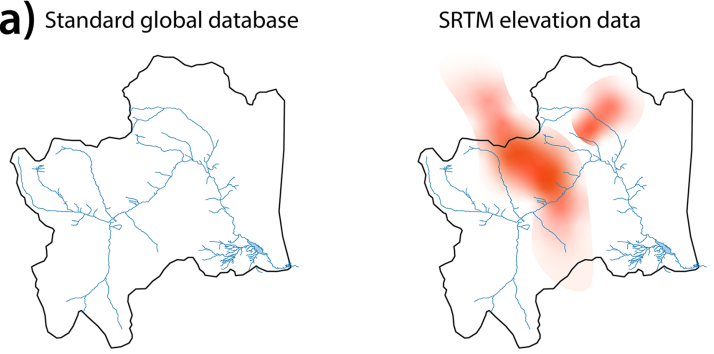

MODIS surface reflectance (linear) MODIS surface reflectance (squared)

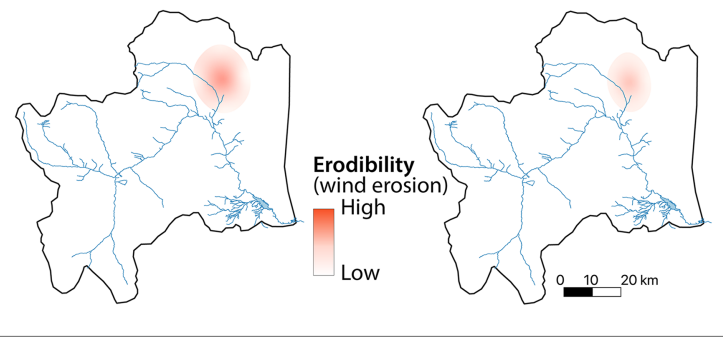

b)
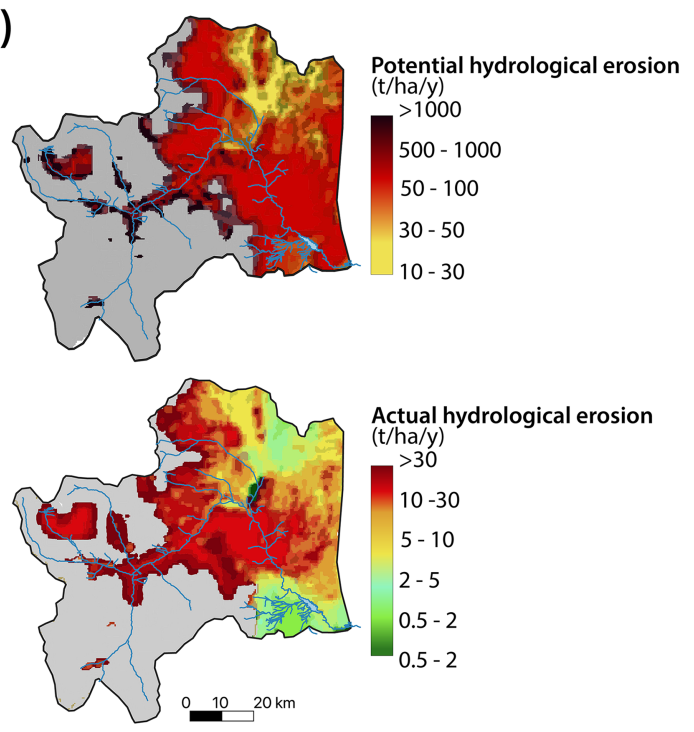

c)

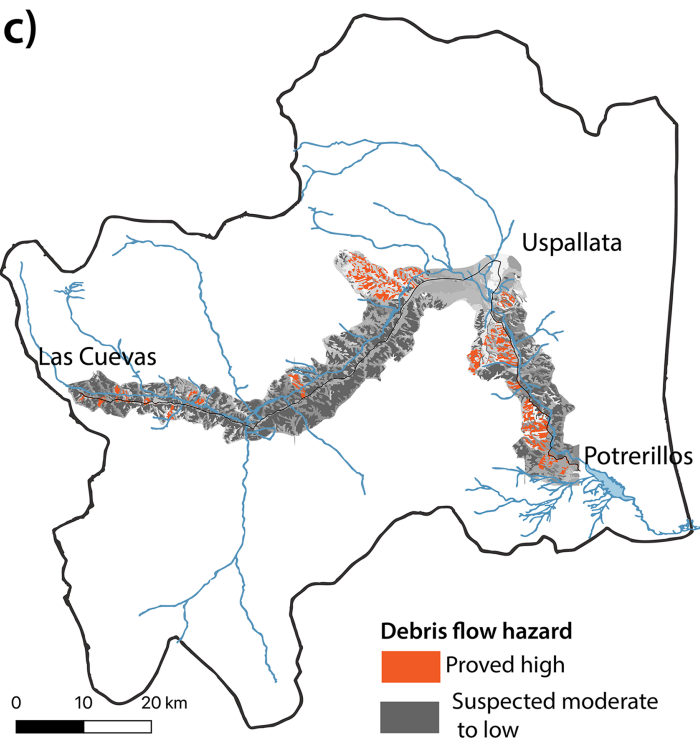

Figure 15. Erosion and erodibility estimates for the Mendoza catchment. (a) Wind erosion soil erodibility maps created using different data sources, after Cremades et al. (2017). (b) Hydrological erosion (actual and potential) based on USLE, after Gaitan et al. (2017). (c) Debris flow hazard map, after Baumann et al. (2011). [Colour figure can be viewed at wileyonlinelibrary.com]
Detrital zircon analysis of Holocene aeolian sand dunes and modern sand samples in the region show that fluvial sediment mixing occurs along a southward (downstream) gradient during wet interglacial periods, while aeolian sediment mixing occurs along a northward gradient during glacial periods (Capaldi et al., 2019). In the Mendoza catchment, analyses using ionic and stable isotopic signatures for the different water sources of the catchment upstream of Potrerillos indicate a larger contribution of the Principal Cordillera than the Frontal Cordillera (Crespo et al., 2017). We can expect to see these findings reflected in our erosion map.

First, we will apply the method to the data from the single detrital sand sample collected downstream of Potrerillos; subsequently, we will include the subcatchment data from sands sampled at Uspallata and Las Cuevas. We will then compare the results to the above-mentioned erosion rate estimates that exist for the different modalities of erosion in the region.

We compute relative frequencies for the river outlet sample by dividing the number of zircons of each age bin by the total number of dated zircons, using an age-bin size of $100 \mathrm{Ma}$. Using Equation (1), we multiply the relative frequency of the river outlet sample by the yearly sediment discharge $Q_{s}\left(\mathrm{~m}^{3}\right.$ $\left.\mathrm{yr}^{-1}\right)$ at this location divided by the pixel size $\left(\mathrm{m}^{2}\right)$. We derive $Q_{s}$ from the infill rate of the Potrerillos reservoir, resulting in a sediment discharge of $14.8 \times 10^{6} \mathrm{~m}^{3} \mathrm{yr}^{-1}$, and the pixel size is $3000 \times 3000 \mathrm{~m}$. As a prior erosion rate estimate, we divide $Q_{s}$ by the total catchment area $\left(7824 \times 10^{6} \mathrm{~m}^{2}\right)$, resulting in a mean erosion rate of $1.9 \mathrm{mmyr}^{-1}$. We use the same $\mathbf{G}$ and parameter values as for the synthetic tests $(\lambda=15 \mathrm{~km}$, a forward error of $1 \%$ and a $\sigma_{m}$ of $10^{-2} \mathrm{myr}^{-1}$ ). The posterior erosion rates show a band of high erosion rates in the Principal Cordillera, surrounded by very low erosion rates, medium to low erosion rates in the Frontal Cordillera and high erosion rates around the Potrerillos reservoir (Figure 16). The normalized posterior variance values are high, with a few exceptions for small geological polygons in the north-east and east of the catchment. The resolution is very small for the blue dot, indicating that the posterior erosion rate predicted at this point depends heavily on the information of surrounding points. This is also reflected in the high spread values over the entire domain.

The mean of the posterior erosion rates is $1.5 \mathrm{mmyr}^{-1}$, close to the mean erosion rate derived from the infill rate of the Potrerillos reservoir. Two possible explanations exist for the band of high erosion rates in the Principal Cordillera. The first hypothesis is that the high erosion rates are caused by glacial erosion, as this region contains many glaciers. The second hypothesis is based on the geological similarity between this part of the Principal Cordillera and the Potrerillos region: both regions are characterized by Neogene fluvial (volcanic)clastic rocks. High erosion rates around Potrerillos - for example, due to the known hillslope instability (Michoud et al., 2016) here - would lead to a larger amount of these Neogene fingerprints in the detrital data, which are redistributed by the inverse model and (mistakenly) interpreted as high posterior erosion rates in the Principal Cordillera. However, from the synthetic examples (see Supporting Information for more details) we know that adding subcatchment data can help distinguish between these two hypotheses as it decouples the erosion rates of these two regions with the same geological unit. The intermediate erosion rates of the Frontal Cordillera correspond well to the predicted actual hydrological erosion of about 30 tha $^{-1}$ $\mathrm{yr}^{-1}$ (taking a sediment density of $1700-2650 \mathrm{~kg} \mathrm{~m}^{-3}$, this corresponds to erosion rates of $1.76-1.13 \mathrm{mmyr}^{-1}$ ). The high erosion rates around the reservoir probably result from mass movements in this area, with observed land sliding velocities up to $6.5 \mathrm{myr}^{-1}$ (Michoud et al., 2016). 

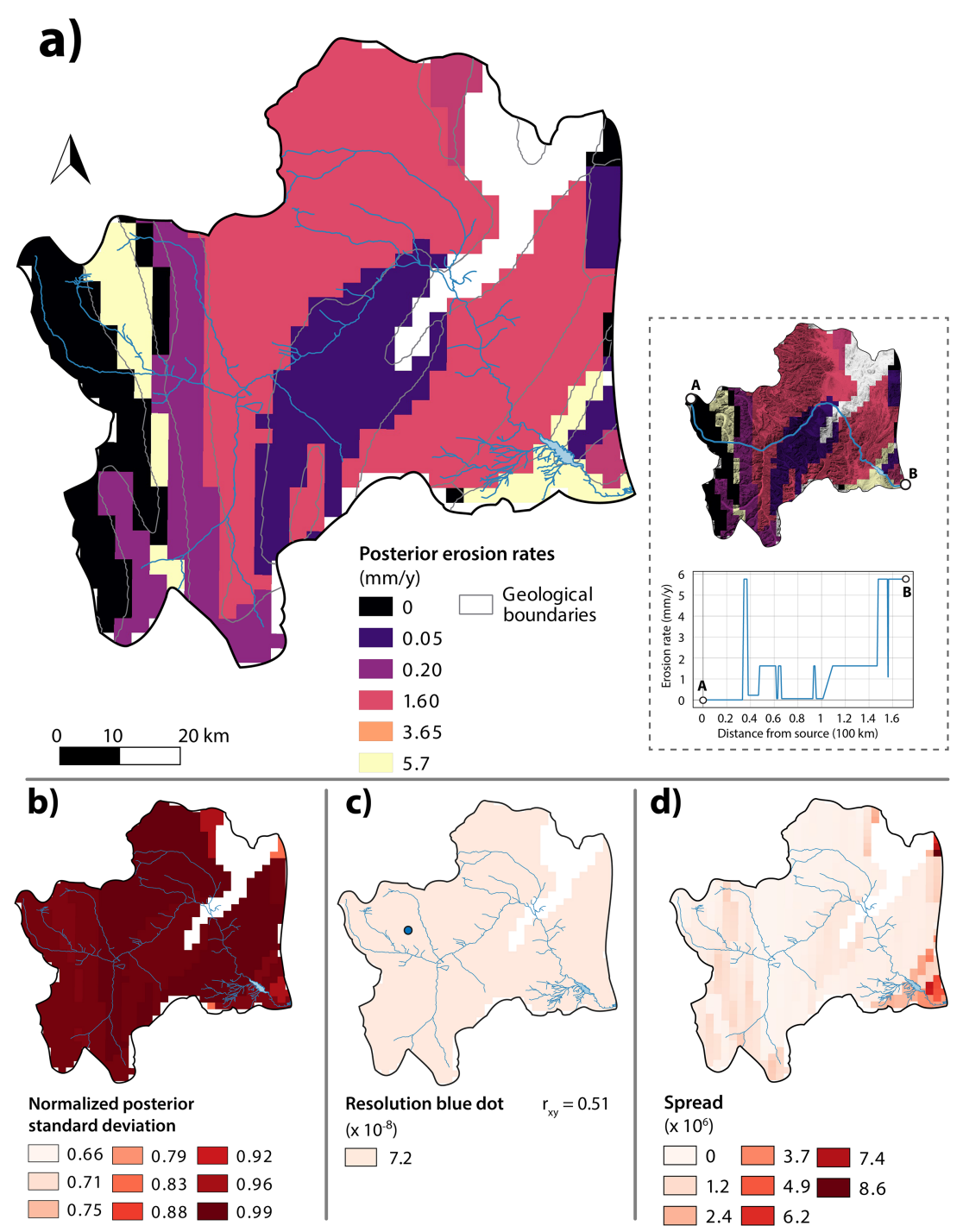

Figure 16. Result of the inverse scheme with detrital zircon data and zircon age spectra for the different geological units. (a) Posterior erosion rates (note that a quantile colour scheme was used); a transect following the main river trunk is given at the right-hand side, following the blue line from point A to point B. (b) Normalized variance. (c) Resolution for the blue dot. (d) Spread function values. The white area is characterized by Quaternary sediments for which no fingerprints were available, so we did not compute erosion rates for this area. [Colour figure can be viewed at wileyonlinelibrary.com]

Now, we add detrital zircon age data of sands sampled near Las Cuevas and Uspallata (Figure 14). The mean erosion rates have now decreased to $1.2 \mathrm{mmy}^{-1}$ and the erosion hotspot has entirely shifted to the surroundings of the Potrerillos reservoir (Figure 17), thereby supporting the second hypothesis that the high erosion rates in the Principal Cordillera in Figure 16a were due to the lithological similarity to the Potrerillos region. Since the erosion rates in the Principal Cordillera are near zero, the region around the Potrerillos reservoir has to account for all of the tracer concentrations of the Neogene fluvial unit in the detrital data, which explains the very high erosion rates in this part of the catchment. The normalized variance map is nearly the same as in Figure 16b, except for the north-western part, where slightly lower values represent the influence of the added data. The sample correlation coefficient has now increased to 0.83 , but the resolution remains very low, indicating the weighted averaging that occurs at the location of the blue dot to constrain the posterior erosion rates. In the spread function map, the locations of the S2 sample and the S1 subcatchment are indicated by higher values.

Caution should be paid when interpreting the posterior erosion rates of the central region of the study area, as the insufficient geological variability of this region results in spatially averaged erosion rates, rather than reflecting the spatial variability that could occur here. Furthermore, the fact that fertility data were only available for two of the eight geological units might have distorted the posterior estimates. Moreover, due to the high hillslope instability of the catchment, perfect sourceto-sink connectivity cannot be guaranteed. These possible storage effects can disturb the fingerprint distribution in the detrital data and therefore also our posterior erosion rate map. Additionally, since the effective scales of (dis)connectivity are strongly variable in time and space (Fryirs, 2013), the unconsolidated sands that were collected by Capaldi et al. (2017) may result from erosion and deposition processes that acted on different timescales, so careful interpretation of the posterior results is needed. Also, single-mineral approaches are more sensitive to durability, winnowing and fertility effects, but multi-proxy approaches can help overcome these issues (e.g. Gaschnig, 2019), which will be illustrated by the next natural example.

Remarkably, although the S2 subcatchment only coincides with the Neogene volcanic unit, which is characterized by one peak in the 0-100 Ma age bin, the detrital zircon ages of the S2 sample show peaks in the 400-500 Ma and the 800$1100 \mathrm{Ma}$ age bins (Figure 14). These older ages are likely from 


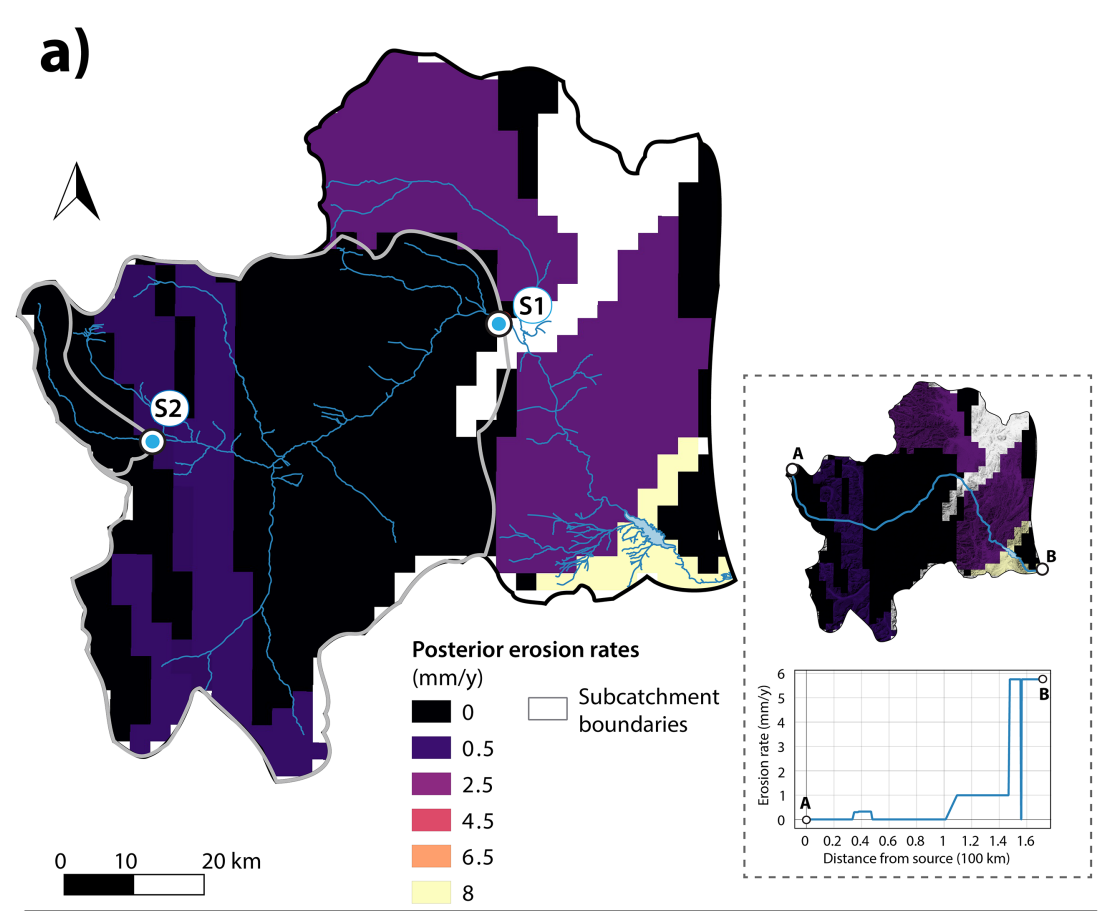

b)

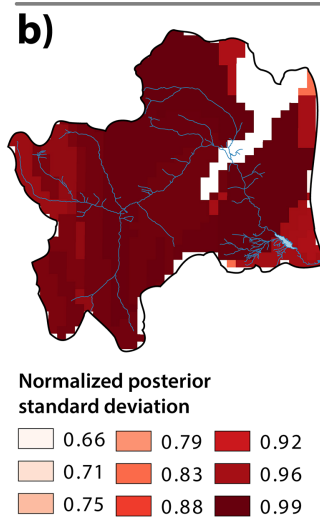

c)

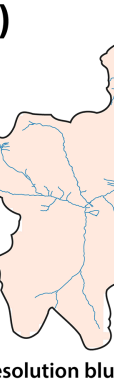

Resolution blue dot $\left(\times 10^{-8}\right)$ d)

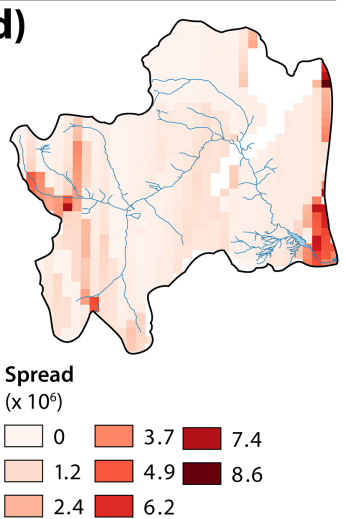

Figure 17. Result of the inverse scheme with detrital zircon data and zircon age spectra for the different geological units and added subcatchment data. (a) Posterior erosion rates (note that a quantile colour scheme was used); subcatchment limits are indicated by grey lines; a transect following the main river trunk is given at the right-hand side, following the blue line from point A to point B. (b) Normalized variance. (c) Resolution for the blue dot. (d) Spread function values. The white area is characterized by Quaternary sediments for which no fingerprints were available, so we did not compute erosion rates for this area. [Colour figure can be viewed at wileyonlinelibrary.com]

the fluvial-clastic rocks that also appear within this catchment. This internal variability within the catchments is unavoidable; however, if this variability can be exploited by collecting more detrital samples, this could further improve the resolution of the inferred rates. An alternative explanation is that aeolian transport has delivered sediments from the Triassic fluvial unit to the west-south-west. This is supported by zircon ages of Holocene sediments of the Andean foreland that show the influence of north-north-eastward palaeowinds that were active during dry, glacial periods in this area (Capaldi et al., 2019). These sorts of complexities could be incorporated into future inverse methods if the dataset requires it.

\section{Marsyandi catchment, Nepal}

In this section we will show how petrological and mineralogical data can be inverted to compute spatially variable erosion rates. The requirements for a suitable study area are: (1) tracer concentration data are available for the different source areas; (2) detrital tracer data exists for sediments sampled at (the outlet of the) river; (3) sediment discharge data are available; (4) the catchment is well connected. We decided to use the Marsyandi catchment as all the requirements are fulfilled for this study area and mineralogical data are made available by Garzanti et al. (2007).

Geologically, the Marsyandi catchment comprises the Tethyan series in the north, the Greater Himalayan units in the centre, delineated by the Main Central Thrust in the south, and the Lesser Himalayan units south of this thrust (Figure 18a). Fluvial denudation rates in the Lesser Himalayan units are estimated to be moderate $\left( \pm 1 \mathrm{mmyr}^{-1}\right.$ ) (Lavé and Avouac, 2001; Bollinger et al., 2004; Pratt-Sitaula et al., 2004), increasing to 3-6 $\mathrm{mmyr}^{-1}$ for the steeper and precipitation-rich Greater Himalayan units (Lavé and Avouac, 2001; Blythe et al., 2007), which gradually decrease northward to $\leq 1 \mathrm{mmyr}^{-1}$ for the northernmost part of the catchment (Lavé and Avouac, 2001; Gabet et al., 2008). Monsoon cycles have a strong impact on sediment storage and transport, as $80 \%$ of the precipitation falls between May and October (Bookhagen, 2010). Estimated from the dilution of the fluvial ${ }^{10} \mathrm{Be}$ signal (Figure 18b), glacial denudation rates are on average $4.6 \pm 0.3 \mathrm{mmyr}^{-1}$, with minima of $\leq 2 \mathrm{mmyr}^{-1}$ in the northernmost Nar tributary catchment and maxima of 4-10 $\mathrm{mmyr}^{-1}$ in the north-western Dudh tributary catchment (Figure 18c). Garzanti et al. (2007) have interpreted their data (that we use 

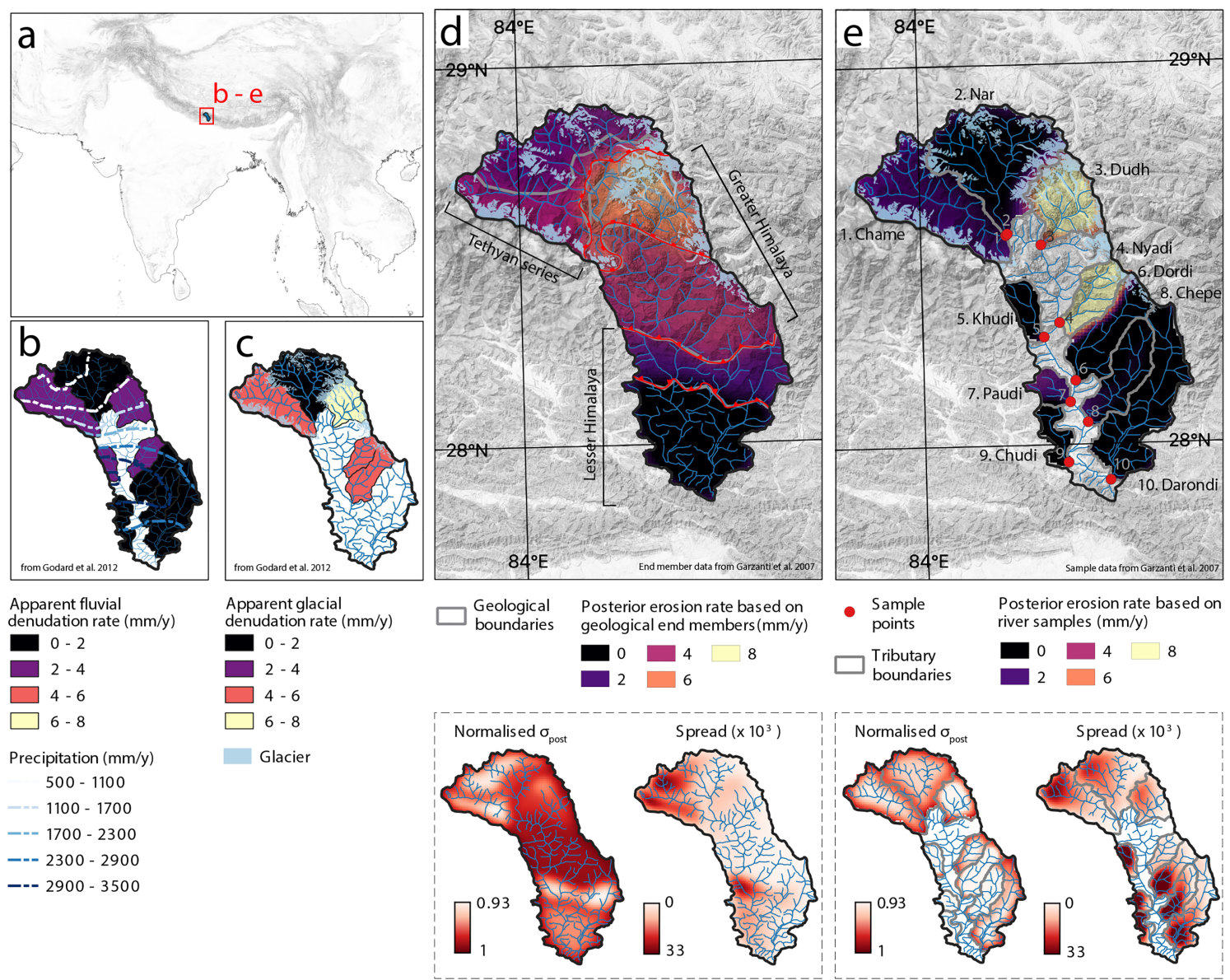

Figure 18. Result of the inverse scheme with detrital mineral data and mineralogical fingerprints for the different source areas of the Marsyandi catchment (data from Garzanti et al., 2007). (a) Location of the study area. (b) Estimated fluvial denudation rates from ${ }^{10}$ Be data after Godard et al. (2012). (c) Estimated glacial denudation rates from ${ }^{10}$ Be data after Godard et al. (2012). (d) Posterior erosion rates calculated from mineralogical end members for the different geological units of the catchment (outlined in grey); mapped below are the normalized variance and spread function for this configuration. (e) Posterior erosion rates calculated from detrital mineralogical data sampled at the outlet of the different tributaries of the catchment (outlined in grey); mapped below are the normalized variance and spread function for this configuration. [Colour figure can be viewed at wileyonlinelibrary.com]

here) as low erosion rates in the north $\left(0.9 \mathrm{mmyr}^{-1}\right.$ for the Chame and Nar subcatchments), intermediate erosion rates in the north-east (2.7 $\mathrm{mmyr}^{-1}$ for the Dudh subcatchment), high erosion rates in the central-eastern part of the catchment (4.5 $\mathrm{mmyr}^{-1}$ for the Nyadi, Dordi and Chepe subcatchments) and low erosion rates in the south-west of the catchment (1.5 $\mathrm{mmyr}^{-1}$ for the Paudi and Chudi subcatchments).

We follow two approaches to illustrate the diversity of settings that are suited for our inversion approach: first we use the geological units as source areas and then we use tributary catchments as source areas. In the first case, source data consist of mineralogical end members computed by Garzanti et al. (2007). In the second case, we use raw mineralogical data of samples of the outlets of the different tributaries, also provided by Garzanti et al. (2007). The detrital data remain the same in both cases, being mineralogical data of sediments of the outlet of the Marsyandi catchment, which were sampled in the monsoon season of 2005.

The resulting posterior erosion rates are in line with the ${ }^{10} \mathrm{Be}-$ derived apparent glacial denudation rates from Godard et al. (2012). Generally, the result also matches the gradient of low erosion rates in the north, a peak in the centre region and a decrease towards the south. Comparing the result of the two approaches, the approach based on geological end members (Figure 18d) corresponds to a spatial averaging of the tributary approach (Figure 18e) since there are more distinct tributaries than there are geological units. This is reflected in lower spread values and higher normalized posterior variance values. With this example we have shown that (1) source areas can be defined as geological units or catchments, and (2) our method works not only for zircon age signatures, but also for a wide variety of other tracers, such as mineralogical data.

\section{Discussion}

We introduced an inverse approach to estimate the spatial variability of erosion rates. The method requires zircon age spectra of the different source areas, knowledge about the zircon fertility of each source area, detrital zircon age data for the catchment outlet and the total yearly sediment export. First, we applied the method to synthetic data and then to detrital zircon age data for the Mendoza catchment, Argentina. With the Marsyandi catchment (Central Nepal Himalayas) example, we showed that the method can be generalized to other tracers and source areas.

The innovation of our method lies in the fact that it requires common and often already existing data. Many traditional methods for erosion rate assessments rely on point measurement data or on steady-state assumptions (Collins and Walling, 2004) - which is often not the case - all of which we do not use in this study. Rather, we solve the under-determined inverse problem that relates the fingerprints found at the outlet of the catchment to the signatures of the different source areas by imposing a spatial correlation between points within the defined smoothing distance. The spread function, resolution matrix and normalized 
variance help to indicate the points where high spatial averaging occurs.

With a prior estimate (equal to the mean erosion rate of the catchment) and the variance we expect around this (governed by the model covariance matrix controlled by the expected model variance $\sigma_{m}$ and the smoothing distance $\lambda$, and the data covariance), we deal with the non-uniqueness of the under-determined problem. There is a trade-off between the reduction of noise in the data (through spatial averaging and smoothing) and the resolution of the model, so the prior variance, smoothing distance and data variance must be chosen carefully.

Moreover, our inversion scheme assumes that the forward model $\mathbf{d}=\mathbf{G} \dot{e}$ is linear. If this is not the case, the posterior solution may deviate strongly from reality. However, we anticipate only small nonlinear effects that can be linearized or treated as a weakly nonlinear problem (e.g. Tarantola, 2005).

With synthetic data that were generated with a forward model, we tested the impact of different variables of the inverse model on the posterior solution, indicating that the number of distinct source areas and the number of tracers have the largest impact. Overall, when the signal of the source areas differs sufficiently, we recovered the true erosion pattern well. We have shown that adding detrital zircon age data from sand sampled within the investigated catchment greatly improves the recovery of more complex erosion rate patterns.

Limitations of the required datasets can distort the posterior erosion rate map. The first limitation entails the connectivity of the catchment, which is often poor due to lakes, dams or other factors impacting the source-sink connection. Nevertheless, our method is useful for the estimation of 'dam corrected erosion rates', taking into account the volume of sediments being held back by obstructions in the streams.

In the Mendoza catchment, frequent mass movements may block the river and the large river terraces indicate sedimentation (Michoud et al., 2016). Multiple remnant and contemporary moraines exist, which may also block the transfer of sediments from source areas to the outlet. The detrital sample has been taken downstream of the Potrerillos reservoir, so sediments originating from far-away source areas possibly do not reach the sample location because they settle upstream. However, should this be the case, adding subcatchment samples could partly alleviate this problem.

The second limitation is centred around residence times, because erosion rates are expressed in volumes per year. Here, we assume little to no storage, or storage generating sediment mixing that corresponds to present-day sediment mixing.

The third limitation comes in when data are multiplied by the total sediment load to obtain absolute - contrary to relative erosion rates. It is difficult to acquire high-confidence sediment load values, since the monitoring of bedload is a lengthy process and is complicated by strong spatial variability (Hinderer et al., 2013). Here, we use the infill rate of the Potrerillos reservoir to obtain the sediment load, based on storage differences of the lake, which possibly also generates a source of error.

The fourth limitation involves the zircon age data. First, selective entrainment may favour the fluvial transport of smaller grains and, if a relationship between age and grain size exists, of certain tracers (e.g. Garzanti et al., 2009). Suspended load is transported more rapidly downstream than sediments travelling near the bed, creating a lag time and possibly a distorted zircon age signal (Granet et al., 2010; Malusà et al., 2013). Dating zircons of widely varying grain sizes can help reconstruct more reliable zircon age distributions of the sampled sands (Ibañez-Mejia et al., 2018). Unfortunately, no grain size data were available for the samples that we use here, so we did not verify whether an age-grain size link exists for the Mendoza catchment. Second, zircon fertilities can vary by three orders of magnitude in the same region, having a large impact on the downstream zircon age spectra (Malusà et al., 2016). We considered the spatial variability of zircon fertilities by applying a scaling factor. The strong resemblance between the synthetic data of Capaldi et al. (2017) and the observed detrital zircon ages of the Mendoza river indicates that spatial variability in zircon fertility is low. However, we have shown with the Marsyandi example that also other tracers such as mineral content can be used to obtain erosion rate maps. Using a multi-proxy approach, many of the aforementioned single-mineral problems disappear.

The inversion scheme that we presented here is versatile and can be used for a wide range of provenance studies, as the zircon age data can simply be replaced by other tracers such as magnetism of minerals, colour of grains, stable isotopes, geochemical components, organic matter concentration and mineralogical properties that are commonly used in provenance studies (Collins et al., 2017). Moreover, the source areas do not need to be defined as geological units: one can, for example, use tributaries for which different fingerprint measurements are available.

\section{Conclusions}

We present an inversion method to calculate spatially variable erosion rates from provenance data, with a focus on $\mathrm{U}-\mathrm{Pb}$ data, starting from a prior erosion estimation, a yearly exported sediment load estimation and source area data. The method relies on the recognition of zircon age signatures of source areas in the zircon age spectrum of modern sands sampled the outlet of the investigated catchment. Therefore, the importance of having different zircon age signatures for each source area must be stressed.

With synthetic data, we have shown that the 'true' solution can be recovered well, using varying parameters; the method is robust and does not depend on one parameter specifically. We also illustrate the use of covariance and resolution to assess the quality of the inferred erosion patterns. The experiments imply that the method is more suited for a well-connected drainage catchment.

Using existing zircon ages of modern sands sampled in the Mendoza catchment, we obtained erosion rates that are in the range of USLE-modelled hydrological erosion rates and the studies on mass movements that have been carried out in the region. The example of the Marsyandi catchment illustrated how the method can be extended to other provenance studies, by replacing the zircon age data by other fingerprint properties and by replacing the geological units with other source areas such as sub-catchments.

Acknowledgements — This research was supported by the Swiss Polar Institute. We thank Thomas N. Capaldi for providing detrital and source area zircon age data of the Mendoza catchment as well as Eduardo Garzanti and others for mineralogical data of the Marsyandi river.

\section{Conflict of Interest}

No conflict of interest has been declared by the authors.

\section{Code and Data Availability}

We provide a simple implementation of the method in Matlab with data used from published sources here: https://github. com/fdedonck/Erosion_Inversion_ESPL 


\section{References}

Amidon WH, Burbank DW, Gehrels GE. 2005. Construction of detrital mineral populations: Insights from mixing of $\mathrm{U}-\mathrm{Pb}$ zircon ages in Himalayan rivers. Basin Research 17(4): 463-485.

Aster RC, Thurber CH. 2013. Parameter Estimation and Inverse Problems, 2. Academic Press: Waltham, MA.

Augustsson C, Voigt T, Bernhart K, Kreißler M, Gaupp R, Gärtner A, Hofmann M, Linnemann U. 2018. Zircon size-age sorting and sourcearea effect: the German Triassic Buntsandstein Group. Sedimentary Geology 375: 218-231.

Backus G, Gilbert F. 1968. The resolving power of gross earth data. Geophysical Journal International 16(2): 169-205.

Barthod LRM, Liu K, Lobb DA, Owens PN, Martínez-Carreras N, Koiter AJ, Petticrew EL, McCullough GK, Liu C, Gaspar L. 2015. Selecting color-based tracers and classifying sediment sources in the assessment of sediment dynamics using sediment source fingerprinting. Journal of Environmental Quality 44(5): 1605-1616.

Baumann V, Wick E, Horton P, Jaboyedoff M. 2011. Debris flow susceptibility mapping at a regional scale along the National Road N7, Argentina, Proceedings of the 14th Pan-American Conference on Soil Mechanics and Geotechnical Engineering, Canadian Geotechnical Society: Richmond, BC.

Blythe AE, Burbank DW, Carter A, Schmidt K, Putkonen J. 2007. PlioQuaternary exhumation history of the central Nepalese Himalaya. 1. Apatite and zircon fission track and apatite $[\mathrm{U}-\mathrm{Th}] / \mathrm{He}$ analyses. Tectonics 26(3).

Bollinger L, Avouac JP, Beyssac O, Catlos EJ, Harrison TM, Grove M, Goffé B, Sapkota S. 2004. Thermal structure and exhumation history of the Lesser Himalaya in central Nepal. Tectonics 23(5).

Bookhagen B. 2010. Appearance of extreme monsoonal rainfall events and their impact on erosion in the Himalaya. Geomatics, Natural Hazards and Risk 1(1): 37-50.

Braun J, Gemignani L, van der Beek P. 2018. Extracting information on the spatial variability in erosion rate stored in detrital cooling age distributions in river sands. Earth Surface Dynamics 6(1): 257-270.

Capaldi TN, Horton BK, McKenzie NR, Stockli DF, Odlum ML. 2017. Sediment provenance in contractional orogens: the detrital zircon record from modern rivers in the Andean fold-thrust belt and foreland basin of western Argentina. Earth and Planetary Science Letters 479: 83-97.

Capaldi TN, George SWM, Hirtz JA, Horton BK, Stockli DF. 2019. Fluvial and eolian sediment mixing during changing climate conditions recorded in Holocene Andean foreland deposits from Argentina (3133ㅇ). Frontiers in Earth Science 7: 298.

Carson CJ, Ague JJ, Grove M, Coath CD, Harrison TM. 2002. U-Pb isotopic behaviour of zircon during upper-amphibolite facies fluid infiltration in the Napier Complex, east Antarctica. Earth and Planetary Science Letters 199(3-4): 287-310.

Casquet C, Baldo E, Pankhurst RJ, Rapela CW, Galindo C, Fanning CM, Saavedra J. 2001. Involvement of the Argentine Precordillera terrane in the Famatinian mobile belt: U-Pb SHRIMP and metamorphic evidence from the Sierra de Pie de Palo. Geology 29(8): 703-706.

Collins AL, Walling DE. 2002. Selecting fingerprint properties for discriminating potential suspended sediment sources in river basins. Journal of Hydrology 261(1-4): 218-244.

Collins AL, Walling DE. 2004. Documenting catchment suspended sediment sources: Problems, approaches and prospects. Progress in Physical Geography: Earth and Environment 28(2): 159-196.

Collins AL, Pulley S, Foster IDL, Gellis A, Porto P, Horowitz AJ. 2017. Sediment source fingerprinting as an aid to catchment management: a review of the current state of knowledge and a methodological decision-tree for end-users. Journal of Environmental Manage 194: 86-108.

Cremades PG, Fernández RP, Allende DG, Mulena GC, Puliafito SE. 2017. High resolution satellite derived erodibility factors for WRF/Chem windblown dust simulations in Argentina. Atmósfera 30 (1): 11-25.

Crespo S, Aranibar J, Gomez L, Schwikowski M, Bruetsch S, Cara L, Villalba R. 2017. Ionic and stable isotope chemistry as indicators of water sources to the Upper Mendoza River basin, Central Andes of Argentina. Hydrological Sciences Journal 62(4): 588-605.
Dickinson WR, Lawton TF, Gehrels GE. 2009. Recycling detrital zircons: a case study from the Cretaceous Bisbee Group of southern Arizona. Geology 37(6): 503-506.

Eberl DD. 2004. Quantitative mineralogy of the Yukon River system: changes with reach and season, and determining sediment provenance. American Mineralogist 89(11-12): 1784-1794.

Fedo CM. 2003. Detrital zircon analysis of the sedimentary record. Reviews in Mineralogy and Geochemistry 53(1): 277-303.

Fox JF, Papanicolaou AN. 2008. Application of the spatial distribution of nitrogen stable isotopes for sediment tracing at the watershed scale. Journal of Hydrology 358(1-2): 46-55.

Fox M, Herman F, Willett SD, May DA. 2014. A linear inversion method to infer exhumation rates in space and time from thermochronometric data. Earth Surface Dynamics 2(1): 47-65.

Fox M, Leith K, Bodin T, Balco G, Shuster DL. 2015. Rate of fluvial incision in the Central Alps constrained through joint inversion of detrital ${ }^{10} \mathrm{Be}$ and thermochronometric data. Earth and Planetary Science Letters 411: 27-36.

Fryirs K. 2013. (Dis)Connectivity in catchment sediment cascades: a fresh look at the sediment delivery problem. Earth Surface Processes and Landforms 38(1): 30-46.

Gabet E, Burbank D, Prattsitaula B, Putkonen J, Bookhagen B. 2008. Modern erosion rates in the High Himalayas of Nepal. Earth and Planetary Science Letters 267(3-4): 482-494.

Gaitan J, Navarro Rau M, Tenti L, Carfagno P, Pizarro MJ, Rigo S. 2017. Estimación de la pérdida de suelo por erosión hídrica en la Republica Argentina. Buenos Aires, Ediciones INTA. Colección: Investigación, desarrollo e innovación. ISBN: 978-987-521-857-4.

Garzanti E. 2016. From static to dynamic provenance analysis: sedimentary petrology upgraded. Sedimentary Geology 336: 3-13.

Garzanti E, Vezzoli G, Andò S, Lavé J, Attal M, France-Lanord C, DeCelles P. 2007. Quantifying sand provenance and erosion (Marsyandi River, Nepal Himalaya). Earth and Planetary Science Letters 258(3-4): 500-515.

Garzanti E, Andò S, Vezzoli G. 2009. Grain-size dependence of sediment composition and environmental bias in provenance studies. Earth and Planetary Science Letters 277(3-4): 422-432.

Gaschnig RM. 2019. Benefits of a multiproxy approach to detrital mineral provenance analysis: an example from the Merrimack River, New England, USA. Geochemistry, Geophysics, Geosystems 20(3): 1557-1573.

Gehrels G. 2014. Detrital zircon U-Pb geochronology applied to tectonics. Annual Review of Earth and Planetary Sciences 42(1): 127-149.

Gingele FX, De Deckker P. 2005. Clay mineral, geochemical and Sr$\mathrm{Nd}$ isotopic fingerprinting of sediments in the Murray-Darling fluvial system, southeast Australia. Australian Journal of Earth Sciences $\mathbf{5 2}$ (6): 965-974.

Godard V, Burbank DW, Bourlès DL, Bookhagen B, Braucher R, Fisher GB. 2012. Impact of glacial erosion on ${ }^{10}$ Be concentrations in fluvial sediments of the Marsyandi catchment, central Nepal. Journal of Geophysical Research: Earth Surface 117(F3).

Granet M, Chabaux F, Stille P, Dosseto A, France-Lanord C, Blaes E. 2010. U-series disequilibria in suspended river sediments and implication for sediment transfer time in alluvial plains: the case of the Himalayan rivers. Geochimica et Cosmochimica Acta 74(10): 2851-2865.

Grauert B, Hänny R, Soptrajanova G. 1973. Age and origin of detrital zircons from the pre-Permian basements of the Bohemian Massif and the Alps. Contributions to Mineralogy and Petrology 40(2): 105-130.

Grimshaw DL, Lewin J. 1980. Source identification for suspended sediments. Journal of Hydrology 47(1-2): 151-162.

Guillon H, Mugnier J-L, Buoncristiani J-F, Carcaillet J, Godon C, Prud'homme C, van der Beek P, Vassallo R. 2015. Improved discrimination of subglacial and periglacial erosion using ${ }^{10} \mathrm{Be}$ concentration measurements in subglacial and supraglacial sediment load of the Bossons glacier (Mont Blanc massif, France). Earth Surface Processes and Landforms 40(9): 1202-1215.

Guo J, Zhang R, Li C, Sun W, Hu Y, Kang D, Wu J. 2018. Genesis of the Gaosong Sn-Cu deposit, Gejiu district, SW China: constraints from in situ LA-ICP-MS cassiterite U-Pb dating and trace element fingerprinting. Ore Geology Reviews 92: 627-642. 
Haddadchi A, Ryder DS, Evrard O, Olley J. 2013. Sediment fingerprinting in fluvial systems: review of tracers, sediment sources and mixing models. International Journal of Sediment Research 28(4): 560-578.

Hatfield RG, Maher BA. 2009. Fingerprinting upland sediment sources: particle size-specific magnetic linkages between soils, lake sediments and suspended sediments. Earth Surface Processes and Landforms 34(10): 1359-1373.

Herman F, Seward D, Valla PG, Carter A, Kohn B, Willett SD, Ehlers TA. 2013. Worldwide acceleration of mountain erosion under a cooling climate. Nature 504(7480): 423-426.

Herman F, Beyssac O, Brughelli M, Lane SN, Leprince S, Adatte T, Lin JYY, Avouac J-P, Cox SC. 2015. Erosion by an Alpine glacier. Science 350(6257): 193-195.

Hinderer M, Kastowski M, Kamelger A, Bartolini C, Schlunegger F. 2013. River loads and modern denudation of the Alps: a review. Earth-Science Reviews 118: 11-44.

Ibañez-Mejia M, Pullen A, Pepper M, Urbani F, Ghoshal G, IbañezMejia JC. 2018. Use and abuse of detrital zircon U-Pb geochronology: a case from the Río Orinoco delta, eastern Venezuela. Geology 46(11): 1019-1022.

Jackson DD. 1979. The use of a priori data to resolve non-uniqueness in linear inversion. Geophysical Journal International 57(1): 137-157.

Keller CB, Boehnke P, Schoene B. 2017. Temporal variation in relative zircon abundance throughout Earth history. Geochemical Perspectives Letters 3: 179-189.

Kleiman LE, Japas MS. 2009. The Choiyoi volcanic province at $34^{\circ} \mathrm{S}-$ $36^{\circ} \mathrm{S}$ (San Rafael, Mendoza, Argentina): implications for the Late Palaeozoic evolution of the southwestern margin of Gondwana. Tectonophysics 473(3): 283-299.

Kurashige Y, Fusejima Y. 1997. Source identification of suspended sediment from grain-size distributions. I. Application of nonparametric statistical tests. CATENA 31(1-2): 39-52.

Lavé J, Avouac JP. 2001. Fluvial incision and tectonic uplift across the Himalayas of central Nepal. Journal of Geophysical Research: Solid Earth 106(B11): 26561-26591.

Everett ME. 2013. Near-surface applied geophysics. Cambridge University Press: Cambridge; 403.

Mackaman-Lofland C, Horton BK, Fuentes F, Constenius KN, McKenzie R, Alvarado PM. 2015. Preliminary depositional and provenance records of Mesozoic basin evolution and Cenozoic shortening in the High Andes, La Ramada fold-thrust belt, southern-central Andes (32-33 $\left.{ }^{\circ} \mathrm{S}\right)$, AGU Fall Meeting Abstracts.

Malusà MG, Carter A, Limoncelli M, Villa IM, Garzanti E. 2013. Bias in detrital zircon geochronology and thermochronometry. Chemical Geology 359: 90-107.

Malusà MG, Resentini A, Garzanti E. 2016. Hydraulic sorting and mineral fertility bias in detrital geochronology. Gondwana Research 31: $1-19$.

Maydagán L, Franchini M, Chiaradia M, Pons J, Impiccini A, Toohey J, Rey R. 2011. Petrology of the Miocene igneous rocks in the Altar region, main Cordillera of San Juan, Argentina: a geodynamic model within the context of the Andean flat-slab segment and metallogenesis. Journal of South American Earth Sciences 32(1): 30-48.

McKenzie NR, Horton BK, Loomis SE, Stockli DF, Planavsky NJ, Lee C-TA. 2016. Continental arc volcanism as the principal driver of icehouse-greenhouse variability. Science 352(6284): 444-447.

Menke W. 1989. Geophysical Data Analysis: Discrete Inverse Theory, rev. edn, International Geophysics Series. Academic Press: San Diego, CA.

Mezger K, Krogstad EJ. 1997. Interpretation of discordant U-Pb zircon ages: an evaluation. Journal of Metamorphic Geology 15(1): 127-140.

Michoud C, Baumann V, Lauknes TR, Penna I, Derron M-H, Jaboyedoff M. 2016. Large slope deformations detection and monitoring along shores of the Potrerillos dam reservoir, Argentina, based on a small-baseline InSAR approach. Landslides 13(3): 451-465.

Moecher D, Samson S. 2006. Differential zircon fertility of source terranes and natural bias in the detrital zircon record: implications for sedimentary provenance analysis. Earth and Planetary Science Letters 247(3-4): 252-266.
Mulcahy SR, Roeske SM, McClelland WC, Jourdan F, Iriondo A, Renne PR, Vervoort JD, Vujovich GI. 2011. Structural evolution of a composite middle to lower crustal section: the Sierra de Pie de Palo, northwest Argentina. Tectonics 30(1): TC1005.

Nibourel L, Herman F, Cox SC, Beyssac O, Lavé J. 2015. Provenance analysis using Raman spectroscopy of carbonaceous material: a case study in the Southern Alps of New Zealand. Journal of Geophysical Research: Earth Surface 120(10): 2056-2079.

Nishiizumi K, Lal D, Klein J, Middleton R, Arnold JR. 1986. Production of ${ }^{10} \mathrm{Be}$ and ${ }^{26} \mathrm{Al}$ by cosmic rays in terrestrial quartz in situ and implications for erosion rates. Nature 319(6049): 134-136.

Oldfield F, Rummery TA, Thompson R, Walling DE. 1979. Identification of suspended sediment sources by means of magnetic measurements: some preliminary results. Water Resources Research 15(2): 211-218.

Pell SD, Williams IS, Chivas AR. 1997. The use of protolith zircon-age fingerprints in determining the protosource areas for some Australian dune sands. Sedimentary Geology 109(3-4): 233-260.

Perg LA, Anderson RS, Finkel RC. 2003. Use of cosmogenic radionuclides as a sediment tracer in the Santa Cruz littoral cell, California, United States. Geology 31(4): 299-302.

Pratt-Sitaula B, Burbank DW, Heimsath A, Ojha T. 2004. Landscape disequilibrium on 1000-10,000 year scales Marsyandi River, Nepal, central Himalaya. Geomorphology 58(1-4): 223-241.

Saylor JE, Sundell KE, Sharman GR. 2019. Characterizing sediment sources by non-negative matrix factorization of detrital geochronological data. Earth and Planetary Science Letters 512: 46-58.

Shaanan U, Rosenbaum G, Campbell MJ. 2019. Detrital fingerprint: the use of early Precambrian zircon age spectra as unique identifiers of Phanerozoic terranes. Earth and Planetary Science Letters 506: 97-103.

Sorby HC. 1849. The structure and origin of the millstone-grit of South Yorkshire. Proceedings of the Yorkshire Geological Society 3: 669-675.

Strazzere L, Gregori DA, Dristas JA. 2006. Genetic evolution of Permo-Triassic volcaniclastic sequences at Uspallata, Mendoza Precordillera, Argentina. Gondwana Research 9(4): 485-499.

Tarantola A. 2005. Inverse Problem Theory and Methods for Model Parameter Estimation. Society for Industrial and Applied Mathematics: Philadelphia, PA.

Tilton GR, Patterson C, Brown H, Inghram M, Hayden R, Hess D, Larsen J. 1955. Isotopic composition and distribution of lead, uranium, and thorium in a Precambrian granite. GSA Bulletin 66(9): 1131-1148.

van Andel TH. 1950. Provenance, transport and deposition of Rhine sediments: a heavy mineral study on river sands from the drainage area of the Rhine. PhD thesis, Groningen.

Vermeesch P. 2004. How many grains are needed for a provenance study? Earth and Planetary Science Letters 224(3-4): 441-451.

Vermeesch P. 2012. On the visualisation of detrital age distributions. Chemical Geology 312-313: 190-194.

Vezzoli G, Garzanti E, Limonta M, Andò S, Yang S. 2016. Erosion patterns in the Changjiang (Yangtze River) catchment revealed by bulk-sample versus single-mineral provenance budgets. Geomorphology 261: 177-192.

Vujovich Gl, van Staal CR, Davis W. 2004. Age constraints on the tectonic evolution and provenance of the Pie de Palo Complex, Cuyania composite terrane, and the Famatinian Orogeny in the Sierra de Pie de Palo, San Juan, Argentina. Gondwana Research 7 (4): 1041-1056

Wall GJ, Wilding LP. 1976. Mineralogy and related parameters of fluvial suspended sediments in northwestern Ohio. Journal of Environmental Quality 5(2): 168-173.

Weltje GJ. 2012. Quantitative models of sediment generation and provenance: state of the art and future developments. Sedimentary Geology 280: 4-20.

Wischmeier WH. 1960. Cropping-management factor evaluations for a universal soil-loss equation. Soil Science Society of America Journal 24(4): 322-326.

Wood PA. 1978. Fine-sediment mineralogy of source rocks and suspended sediment, Rother catchment, West Sussex. Earth Surface Processes 3(3): 255-263. 
Yang X, Zhang F, Fu X, Wang X. 2008. Oxygen isotopic compositions of quartz in the sand seas and sandy lands of northern China and their implications for understanding the provenances of aeolian sands. Geomorphology 102(2): 278-285.

Yu L, Oldfield F. 1993. Quantitative sediment source ascription using magnetic measurements in a reservoir-catchment system near Nijar, S.E. Spain. Earth Surface Processes and Landforms 18(5): 441-454.

\section{Supporting Information}

Additional supporting information may be found online in the Supporting Information section at the end of the article. 